Chinese Journal of Organic Chemistry

\title{
芳酮类化合物的合成研究进展
}

\author{
刘亮 ${ }^{a}$ 刘文波 ${ }^{a}$ 崔冬梅 ${ }^{b}$ 曾 明*,a \\ ( ${ }^{a}$ 九江学院药学与生命科学学院 江西九江 332005) \\ ( $b$ 浙江工业大学药学院 杭州 310014)
}

\begin{abstract}
摘要 芳酮类化合物具有多种生物活性，同时也是重要的精细化工品，因此其合成方法受到了广泛关注. 对近五至八 年来芳酮类化合物的合成方法进行总结，通过对其反应机理进行探讨，将这些反应大致分为三类，即通过过渡金属催 化机理的偶联反应、通过自由基机理的反应及通过其他机理的反应，期望为芳酮类化合物的合成新方法提供启发.

关键词 芳甲酰基; 反应机理; 合成方法
\end{abstract}

\section{Progress in the Synthesis of Aroyl Compounds}

\author{
Liu, Liang $^{a} \quad$ Liu, Wenbo $^{a} \quad$ Cui, Dong-Mei ${ }^{b}$ Zeng, Ming ${ }^{*, a}$ \\ ( ${ }^{a}$ School of Pharmacy and Life Science, Jiujiang University, Jiujiang, Jiangxi 332005) \\ ( ${ }^{b}$ College of Pharmaceutical Science, Zhejiang University of Technology, Hangzhou 310014)
}

\begin{abstract}
Aroyl compounds exhibit various biological activities and are important fine chemicals as well. Therefore, their synthetic methods have attracted considerable attention. It is the first time to summarize the synthetic methods of aroyl compounds in the past five to eight years. These reactions can be classified into three parts by their reaction mechanism, namely, coupling reaction catalyzed transition metals, the free radical mechanism and aromylation reactions carried out by other mechanisms. It is expected that inspiration of new synthetic methods will be provided for the synthesis of compounds bear aroyl group in this review.
\end{abstract}

Keywords aroyl group; reaction mechanism; synthetic method

芳酮类化合物具有抗肿瘤 ${ }^{[1-4]}$ 、抗炎 ${ }^{[5,6]}$ 、抗菌 ${ }^{[7,8]}$ 、 抗氧化 ${ }^{[9]}$ 等多种生物活性, 该结构单元广泛存在于天然 产物、药品、农药、香料及电子材料中; 同时, 芳酮类 化合物是一类重要有机化工砌块 ${ }^{[10]}$, 是有机合成中重 要的亲电试剂, 可以广泛地应用于功能化有机小分子的 转化. 芳酮类化合物的合成方法主要可以概括为以下几 类: (1)使用芳烃和酰氯在三氯化铁条件下经傅克酰基化 反应合成芳酮类化合物 ${ }^{[1-16]}$; (2)使用醛和格氏试剂通过 格氏反应/氧化等步骤合成芳酮化合物; (3)通过有机金 属试剂与 Weinreb 酰胺经 1,2-加成合成芳酮类化合物; (4)以一氧化碳(包括固体一氧化碳源)为羰基源, 经金属 催化一氧化碳插入合成芳酮类化合物; (5)以酮、羧酸、 羧酸酯等为羰基源, 经 $\mathrm{C}-\mathrm{H}$ 活化、氧化加成、还原消
除等反应合成芳酮类化合物; (6)以活泼亚甲基、氧基和 氧气、水等其他小分子为羰基源经缩合、氧化、水解等 反应合成芳酮类化合物. 通过对这些合成芳酮类化合物 方法的反应机理进行分析和归纳, 这些反应大致可以分 为三类，即过渡金属催化机理的偶联反应、自由基机理 的反应及其他机理的芳甲酰基化反应. 本文主要从以上 三类机理的角度对近五至八年来芳酮类化合物的合成 方法进行综述, 并对反应机理进行探讨, 希望为具有功 能化、附加值高的芳酮类化合物新方法的开发提供思路.

\section{1 通过过渡金属催化机理的偶联反应}

\section{1 以钯为催化剂}

在过渡金属催化条件下以气态的一氧化碳为羰基

\footnotetext{
* Corresponding author. E-mail: zengming@zjut.edu.cn

Received April 25, 2021; revised June 7, 2021; published online July 5, 2021.

Project supported by the National Natural Science Foundation of China (No. 21967013), the Natural Science Foundation of Jiangxi Province (No. 21967013), the Foundation of Jiangxi Provincial Department of Education (No. GJJ201825), and the Science and Technology Project of Jiangxi Provincial Health Committee (No. 202131074).

国家自然科学基金(No. 21967013)、江西省自然科学基金青年基金(No. 21967013)、江西省教育厅基金(No. GJJ201825)、江西省卫生建康委科技计划 (No. 202131074)资助项目.
} 
源，经类似的 Suzuki 偶联反应是制备芳基酸、芳基酮、 芳基酯、酰胺、芳基醛等化合物的重要方法, Beller 等 ${ }^{[15]}$ 在 2009 年对该方法进行了综述性的报道. 目前该方法 也是合成芳酮类化合物的重要手段之一.

2009 年, Florent 等 ${ }^{[17]}$ 报道了在一氧化碳氛围下, 以 $\mathrm{PdCl}_{2}$ 为催化剂, 1,1 -二溴-(2-氨基)芳乙烯和芳基硼酸合 成 2-芳甲酰基吲哚衍生物的方法，收率达 71\% (Eq. 1).

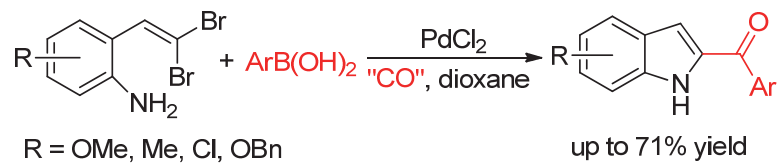

2015 年, 关正辉课题组 ${ }^{[18]}$ 报道了一种新型的合成 3-芳甲基酮取代的吲哚衍生物的方法. 该反应以 $\mathrm{Pd}(\mathrm{OAc})_{2}$ 为催化剂, 吲哚衍生物和苯硼酸为原料, 一氧 化碳作为羰基源, 反应条件温和. 底物适用性研究表明, 当 $\mathrm{R}^{1}$ 为烷基(Me、Et)取代时, 底物适用性良好, 收率达 $82 \%$; 然而当 $\mathrm{R}^{1}$ 为芳基取代时, 反应几乎不发生(Eq. 2).

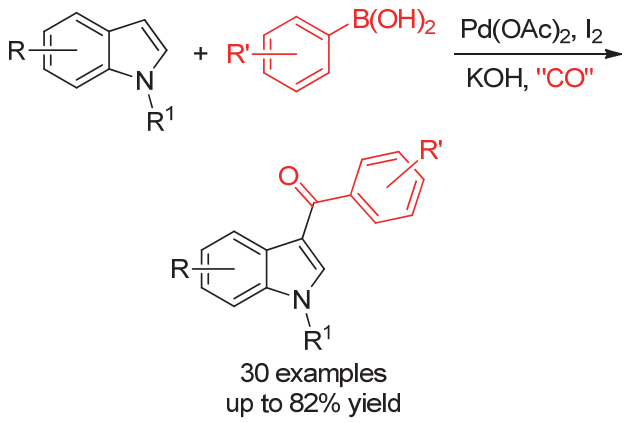

他们提出了两种可能的反应机理(Scheme 1): (1)吲 哚衍生物在碘单质条件下首先转化为 3 -碘代吲哚, 然后

Path A

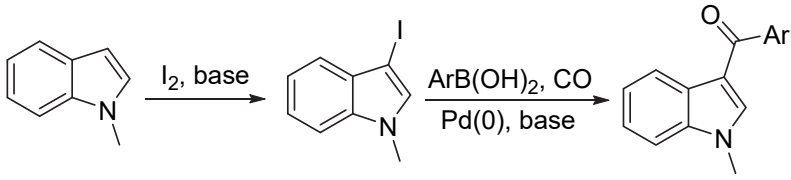

Path B

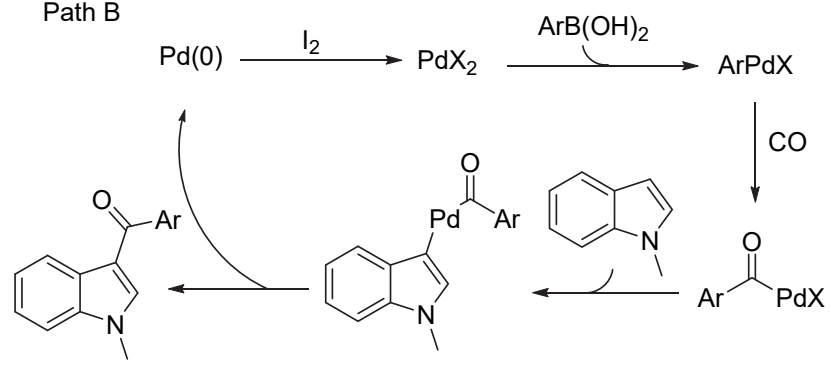

图式 1 合成 3-芳甲酰基吲哚可能的反应机理

Scheme 1 Possible reaction mechanism for the synthesis of 3-Aroyl indole
与一氧化碳、芳基硼酸在零价钯催化作用下得到目标化 合物(Path A); (2)首先零价钯在碘单质条件下被氧化为 二价钯，让芳基碀酸在二价钯作用下形成 Ar-Pd-X 中间 体，该中间体插入一氧化碳后进一步与吲哚衍生物反应 得到目标化合物(Path B).

2016 年, Arndtsen 等 ${ }^{[19]}$ 在上述工作基础上开发了芳 甲酰基取代的吡咯、咪唑、苯并啞唑、呋喃等化合物的 合成方法. 该反应以碘代芳烃和含氮杂环(吡咯、咪唑、 苯并啞唑、呋喃等)为原料, 以 $\operatorname{Pd}\left(\mathrm{P}^{t} \mathrm{Bu}_{3}\right)_{2}$ 为催化剂, $\mathrm{NEt}^{t} \mathrm{Pr}_{2}$ 为碱, 乙腈为溶剂, 一氧化碳为羰基源, 收率为 $56 \% \sim 86 \%$ (Eq. 3 ).

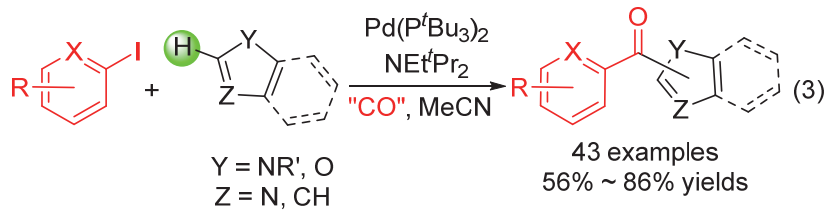

他们对反应机理进行了推测(以 $N$-取代吡咯为例) (Scheme 2). 首先, 碘代芳烃和一氧化碳在钯作用下形 成 $\operatorname{Ar}(\mathrm{CO}) \mathrm{PdL}_{n} \mathrm{I}$ 的复合物，该复合物与吡咯反应可能通 过三种反应历程得到目标产物: (a) $\operatorname{Ar}(\mathrm{CO}) \mathrm{PdL}_{n} \mathrm{I}$ 复合物 经还原消除反应转化为碘代芳甲酤, 然后与 $N$-取代吡 咯在碱性条件下反应，脱去一分子碘化氢得到目标化合 物 (Path a); 另外一方面, 他们认为 $N$-取代吡咯与 $\operatorname{Ar}(\mathrm{CO}) \mathrm{PdL}_{n} \mathrm{I}$ 复合物作用得到目标化合物(Path b); 值得 一提得是, 文章指出 $\operatorname{Ar}(\mathrm{CO}) \mathrm{PdL}_{n} \mathrm{I}$ 复合物能与 $N$-取代吡 咯作用脱去一分子碘化氢形成含吡咯的中间体，最后通 过还原消除反应得到目标化合物(Path c).

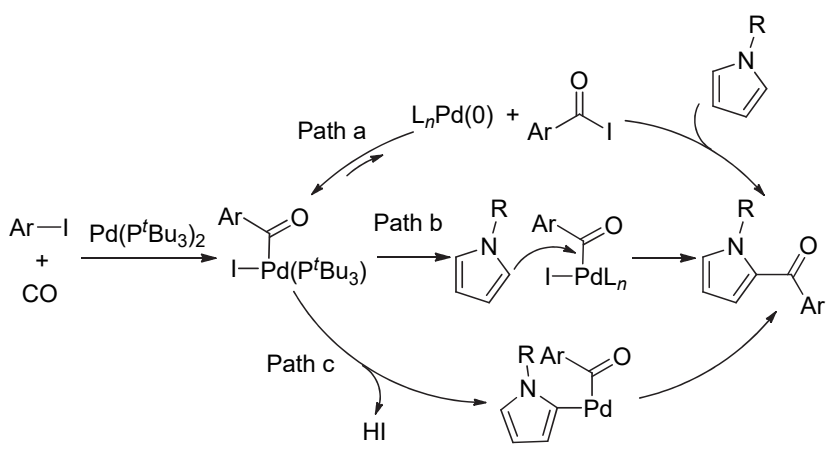

图式 2 可能的反应机理

Scheme 2 Possible reaction mechanism

2015 年, Skrydstrup 等 ${ }^{[20]}$ 以溴代芳烃和多氟芳烃为 原料, 以一氧化碳为羰基源, 在 $\mathrm{Pd}(\mathrm{TFA})_{2} / \mathrm{P}(t-\mathrm{Bu})_{3}$ 催化 下经碳氢活化合成了多氟取代的芳基甲酮衍生物，并将 该方法应用于一氧化氮合成酶抑制剂的合成(Eq. 4). 


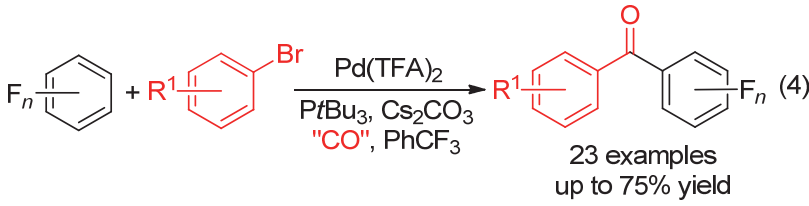

2018 年, Arndtsen 等 ${ }^{[21]}$ 对上述反应进行了改进, 他 们发现当以 $[\mathrm{Pd}(\mathrm{allyl}) \mathrm{Cl}]_{2}$ 为催化剂, 在一氧化碳氛围下, 碘代芳烃和芳烃直接经碳氢活化反应插入羰基合成芳 酮类化合物, 收率达 $99 \%$, 应用性广泛, 适用于各类二 芳基甲酮类化合物的合成(Eq. 5).

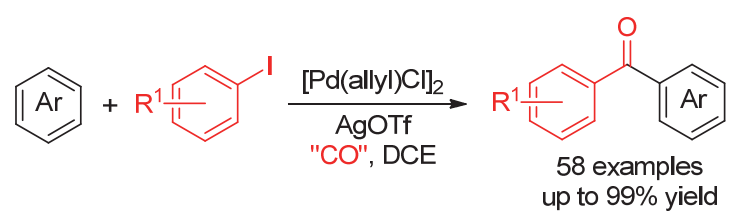

2020 年, 该研究小组 ${ }^{[22]}$ 报道了在 $[\mathrm{Pd}(\text { allyl }) \mathrm{Cl}]_{2} /$ $\mathrm{AgOTf}$ 的催化下, 以碘单质为氧化剂, 一氧化碳的氛围 下将芳烃转化为二芳基甲酮的方法, 收率高达 99\%, 适 用于各种对称或不对称的二芳基甲酮的制备(Eq. 6).

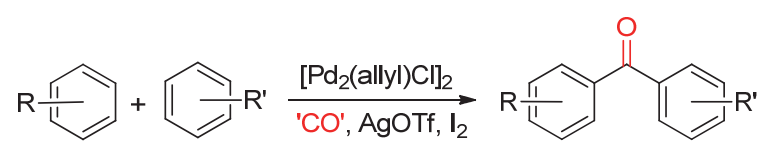

up to $99 \%$ yield

他们认为该反应过程涉及到重要的中间体 IV 的形 成, 并提出了以下三种与中间体 IV 相关的反应机理[即 二价钯 $\operatorname{Pd}(\mathrm{II})$ 循环和零价钯 $\operatorname{Pd}(0)$ 循环] (Scheme 3): (1) 首
先钯与三氟甲磺酸银结合形成二价钯配合物 $\mathbf{I}$, 然后在 一氧化碳作用下形成中间体 II, 零价钯 $\operatorname{Pd}(0)$ 离去, 最 后，中间体 II 与两分子芳烃作用得到对称的芳基甲酮类 化合物(Path A); (2)二价钯配合物 I 与芳烃作用得到中间 体 III, 在一氧化碳作用下中间体 III 被还原成零价钯 $\operatorname{Pd}(0)$, 同时生成重要的中间体 IV, 最后，中间体 IV 与 芳烃反应生成目标产物, 零价钯在碘单质作用下转化为 二价钯 $\mathrm{Pd}(\mathrm{II})$ (Path B); (3)此外, 芳烃和碘单质在三氟甲 磺酸银作用下生成碘代芳烃, 然后碘代芳烃与零价钯发 生氧化加成反应得到中间体 $\mathbf{V}, \mathbf{V}$ 在三氟甲磺酸银和一 氧化碳作用下插入羰基, 最后发生消除反应得到重要的 中间体芳甲酰基三氟甲磺酸, 进一步与芳烃作用得目标 化合物(Path C).

2016 年, Arndtsen 等 ${ }^{[23]}$ 报道了在 $\operatorname{Pd}(\mathrm{bda})_{3}$ 催化条件 下，以溴苯或碘苯和 4-二甲氨基吡啶为原料, $\mathrm{P}^{t} \mathrm{Bu}_{3}$ 为配 体，一氧化碳作为羰基源合成具有亲电性的 ArCO-4-二 甲氨基吡啶(DMAP)盐的方法. 2018 年，该小组 ${ }^{[24]}$ 对上 述反应进行了改进, 他们发现当以 $\operatorname{Pd}\left(\mathrm{P}^{t} \mathrm{Bu}_{3}\right)_{2}$ 为催化剂, 4,5-双 (二苯基膦)-9,9-二甲基氧杂葱 (Xantphos)为配体 时, 氯苯在相同条件下也可以转化为 ArCO-DMAP 盐, 并应用该盐通过酰化反应合成大量的酰胺类化合物，底 物适用性广泛(Eq. 7).

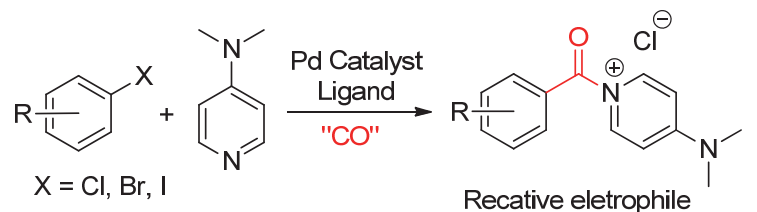

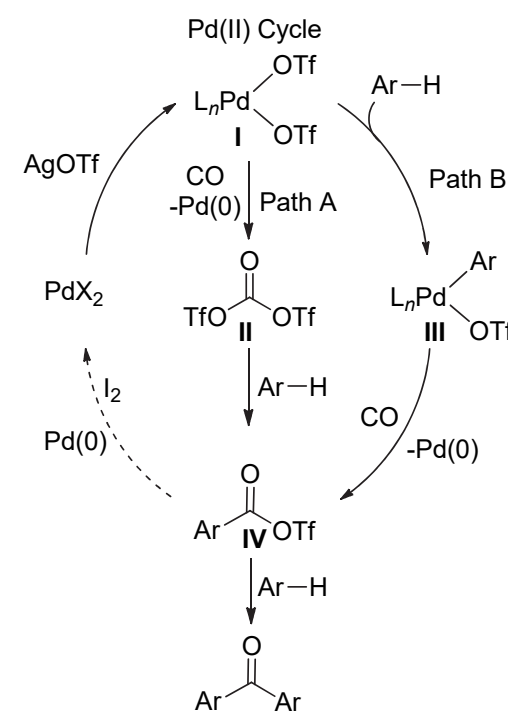

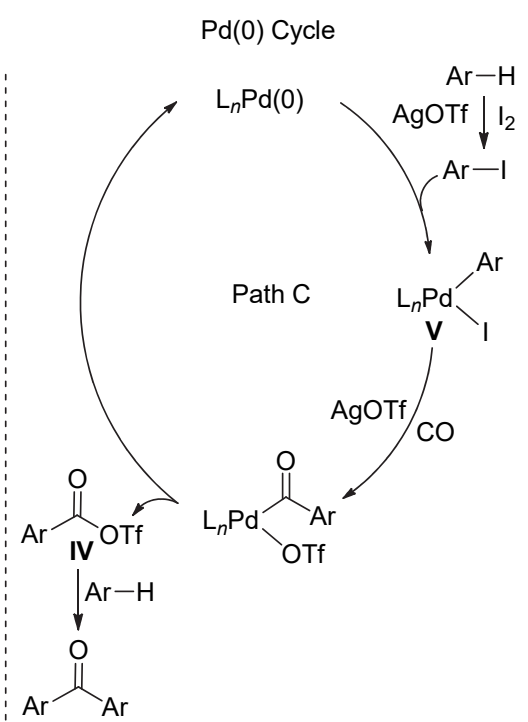

图式 3 合成二芳基甲酮可能的反应机理

Scheme 3 Possible reaction mechanism for the synthesis of diaryl ketone 
该研究小组 ${ }^{[23]}$ 提出了以下可能的反应机理(Scheme 4): 首先，配体与钯催化剂结合成稳定的配合物 I, 然 后，钯配合物与卤代芳烃通过氧化加成反应形成复合物 II，最后，在一氧化碳氛围下插入羰基，在碱性条件下 经还原消除等过程得到 ArCO-DMAP 盐.

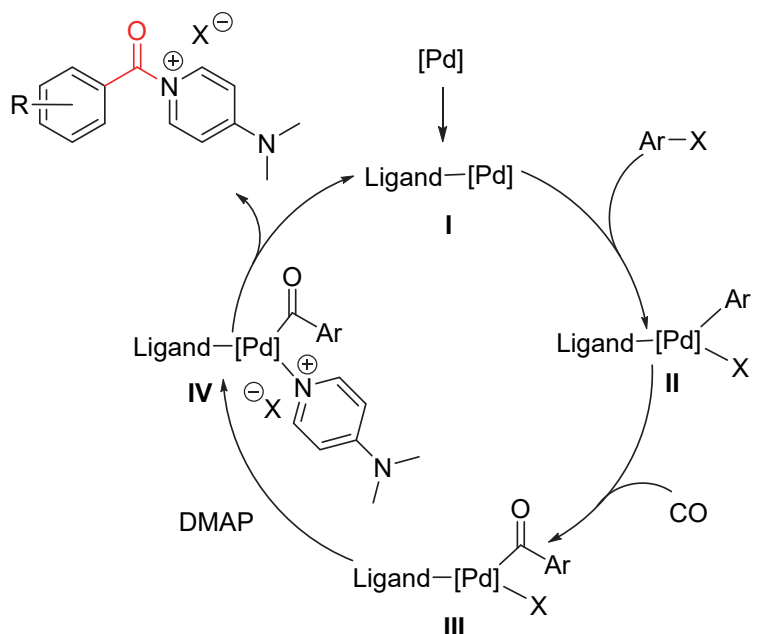

图式 4 合成二甲氨基吡啶盐可能的反应机理

Scheme 4 Possible reaction mechanism for the synthesis of dimethylaminopyridinium salts

金属羰基化合物 $\mathrm{M}(\mathrm{CO})_{n}$ 通过在微波或者高温下释 放一氧化碳作为固体羰基源 ${ }^{[25-28]}$, 有利于避免气态一氧 化碳的使用. 2011 年, Kashani 等 ${ }^{[29]}$ 报道了在 $140{ }^{\circ} \mathrm{C}$ 条件 下, 以醋酸钯为催化剂, 碳酸钾为碱, 苯甲醚为溶剂, $\mathrm{Mo}(\mathrm{CO})_{6}$ 为羰基源，以磑代芳烃与芳基硼酸为原料合成 二芳基酮类衍生物，收率为 $60 \%$ ～ $86 \%$. 该反应需要在 高温下进行，需加入过量的芳基硼酸、碱及 $\mathrm{Mo}(\mathrm{CO})_{6}$, 在一定程度上限制了该方法的适用性. 2019 年, $\mathrm{Hu}$ 等 ${ }^{[30]}$ 对该方法进行了改进，他们发现以三氟甲磺酸钯为催化 剂, 乙腈和水的混合溶液 $(V: V=4: 6)$ 为溶剂时, $\mathrm{Mo}(\mathrm{CO})_{6}$ 的用量降为 0.5 equiv., 反应温度为 $50{ }^{\circ} \mathrm{C}$, 反 应能顺利进行. 该课题组将反应置于一氧化碳氛围下, 发现在相同条件下得到的是碳碳偶联产物，因而排除了 羰基化过程与一氧化碳的逸出有关(Eq. 8).

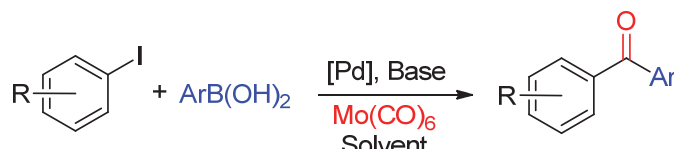

Kashani's work $\mathrm{Pd}(\mathrm{OAc})_{2}, \mathrm{~K}_{2} \mathrm{CO}_{3}$, anisole, $140^{\circ} \mathrm{C}$ Hu's work $\quad \mathrm{Pd}(\mathrm{TFA})_{2}, \mathrm{~K}_{3} \mathrm{PO}_{4}, \mathrm{CH}_{3} \mathrm{CN} / \mathrm{H}_{2} \mathrm{O}(\mathrm{V}: \mathrm{V}=4: 6), 50^{\circ} \mathrm{C}$

2020 年, Bayer 等 ${ }^{[31]}$ 报道了一种绿色、环保的合成 二芳基甲酮类化合物的方法. 他们以溴代芳烃和芳基硼 酸类化合物为原料，乙酰丙酮钯为催化剂，二(1-金刚烷 基)-正丁基膦氢碘化物(CataXCium AHI)为配体，氢氧
化钠为碱，9-甲基-9H-芴-9-羰基氯(COgen)为羰基源，在 柠檬烯中反应 $18 \mathrm{~h}$ 左右可制得二芳基甲酮类化合物，收 率达 96\%，该反应底物适用性广泛，同时适用于芳甲酰 胺、芳酸酯类化合物的合成. 该类反应溶剂可以回收、 循环使用，有利于工业化生产(Eq. 9).

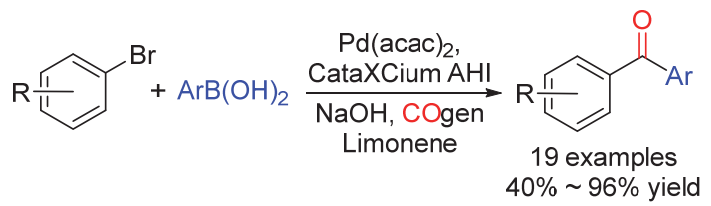

2011 年, Koichiro 等 ${ }^{[32]}$ 报道了一种以碘代芳烃和胺 类化合物为原料，双(二羰基化二茂铁)为羰基源合成芳 甲酮类化合物的方法，双(二羰基化二茂铁)作为新型的 固体羰基源，与 $\mathrm{Mo}(\mathrm{CO})_{6}$ 相比，性质相对稳定，可操作 性强; 2018 年, Nordeman 等 ${ }^{[33]}$ 对该方法进行了改进, 他 们发现在微波条件下，溴代芳烃与胺类化合物反应也能 顺利发生(Eq. 10)

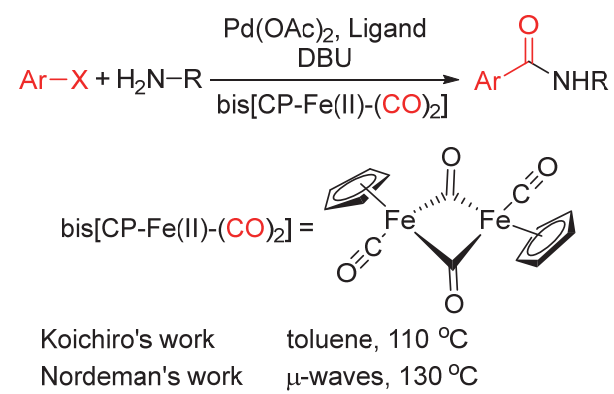

2017 年，吴小锋课题组 ${ }^{[34]}$ 以 $\mathrm{Mo}(\mathrm{CO})_{6}$ 为羰基源，以 碘代芳烃和苯并异噁唑为原料, $\mathrm{Pd} / \mathrm{C}$ 为催化剂, 三乙胺 为碱，四丁基溴化铵为添加剂，经开环、羰基插入等步 骤合成了芳甲酰胺类化合物。该反应以水作为溶剂，催 化剂 $\mathrm{Pd} / \mathrm{C}$ 可回收使用, 而且反应过程中不需要惰性气 体保护，反应操作简便，绿色环保(Eq. 11).

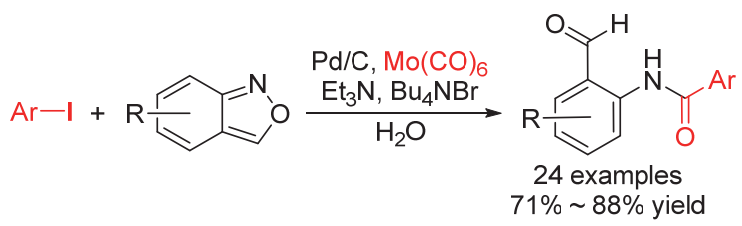

2018 年, 吴小锋课题组 ${ }^{[35]}$ 以 $\mathrm{Mo}(\mathrm{CO})_{6}$ 为羰基源，芳 基乙烯和硝基取代的芳烃为原料，在乙酰丙酮钯催化条 件下合成了芳乙烯基取代的酰胺类化合物，收率达 $86 \%$ ，该反应底物廉价易得。在该反应中 $\mathrm{Mo}(\mathrm{CO})_{6}$ 起到 了还原剂和羰基源的双重作用，机理研究表明，硝基芳 烃在钯催化剂的循环中起到重要作用(Eq. 12). 


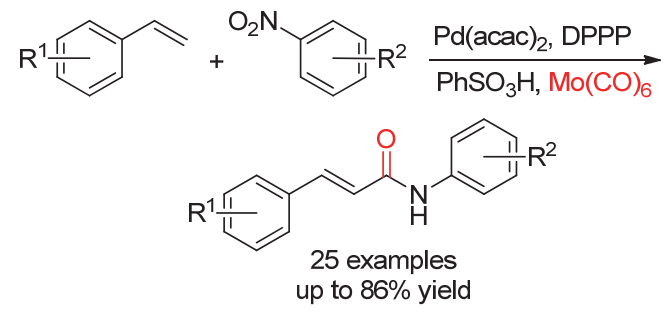

该反应可能的机理如 Scheme 5 所示: 首先, 硝基苯 在 $\mathrm{Mo}(\mathrm{CO})_{6}$ 的作用下与 $\mathrm{LPdX}_{2}$ 反应生成中间体 $\mathbf{I}$, 然后, $\mathrm{LPdX}_{2}$ 与苯乙烯配位形成中间体 $\mathbf{I}$, 再通过迁移、插入 等过程得到中间体 II, 最后经一氧化碳插入、还原消除 等反应得到目标化合物.

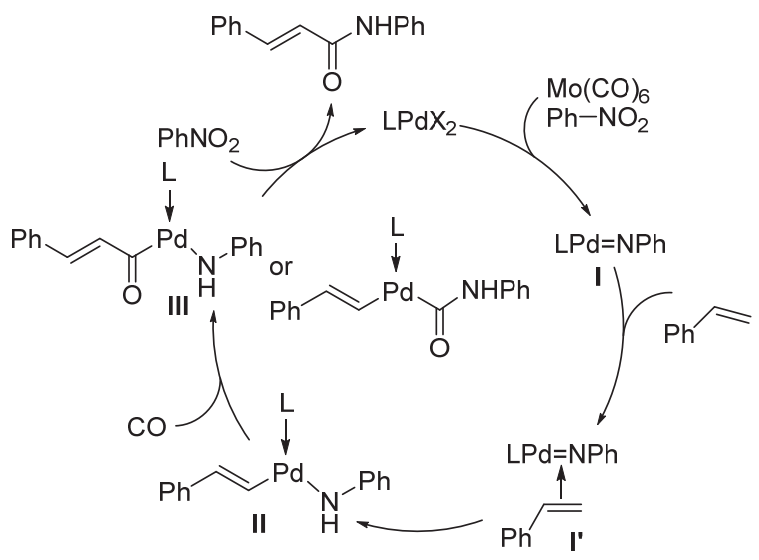

图式 5 合成芳基酰胺可能的反应机理

Scheme 5 Possible reaction mechanism for the synthesis of arylamide

2020 年, 吴小峰课题组 ${ }^{[36]}$ 开发了在钯催化条件下 以炔丙基醇和芳基三氟甲磺酸酯经双羰基环化反应合 成 4-芳甲酰基呋喃酮类化合物的方法. 该反应以 $\mathrm{Pd}(\mathrm{OAc})_{2}$ 为催化剂, $\mathrm{Cr}(\mathrm{CO})_{6}$ 为羰基源, $N, N$-二甲基甲酰 胺(DMF)为溶剂, 反应收率达 $92 \%$. 然而, 当芳基三氟 甲磺酸酯的苯环含有缺电子基如 $\mathrm{Br} 、 \mathrm{CN}$ 或芳基为其他 芳香杂环(噻吩、吡啶)时, 反应几乎不发生(Eq. 13).

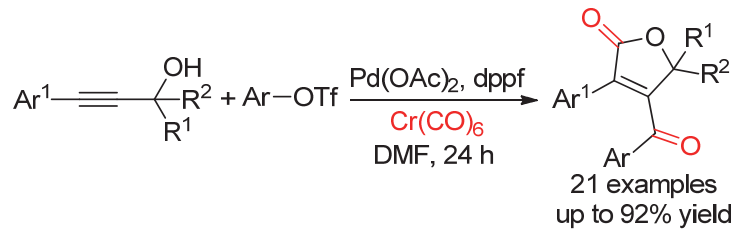

2020 年, 吴小峰课题组 ${ }^{[37]}$ 又报道了以炔丙基胺和 卤代芳烃为原料合成 $N$-芳甲酰基类吡咯酮的新方法. 该反应以乙酰丙酮钯为催化剂, 1, 1'-双(二苯基膦)二茂 铁(DPPF)为配体, 苯-1,3,5-三甲酸三酯(TFBen)为羰基 源, 收率达 91\%. 该反应中, 碘代芳烃与溴代芳烃反应 性相当(Eq. 14).

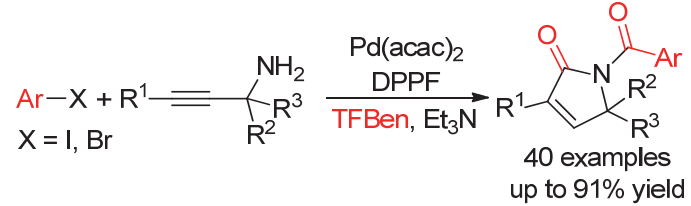

他们认为该反应是按以下机理进行(Scheme 6): 首 先, $\operatorname{Pd}(\mathrm{acac})_{2}$ 在 $\mathrm{DPPF}$ 作用下转化为零价钯配合物 $\mathrm{L}-\mathrm{Pd}(0)$, 再与 $\operatorname{ArX}$ 发生氧化加成反应形成二价钯配合 物 $\operatorname{ArPd}(\mathrm{II}) \mathrm{LX}$; 然后在一氧化碳作用下插入羰基形成 $\operatorname{Ar}(\mathrm{CO}) \operatorname{Pd}(\mathrm{II}) \mathrm{LX}, \operatorname{Ar}(\mathrm{CO}) \mathrm{Pd}(\mathrm{II}) \mathrm{LX}$ 进一步与 2,2-二甲基 苯丙炔胺在碱性条件下反应得到中间体 II，中间体 II 在 零价钯配合物 L-Pd(0)作用下形成五元环中间体 III; 最 后，中间体 III 在一氧化碳作用下经羰基插入、还原消 除等过程得到目标化合物.

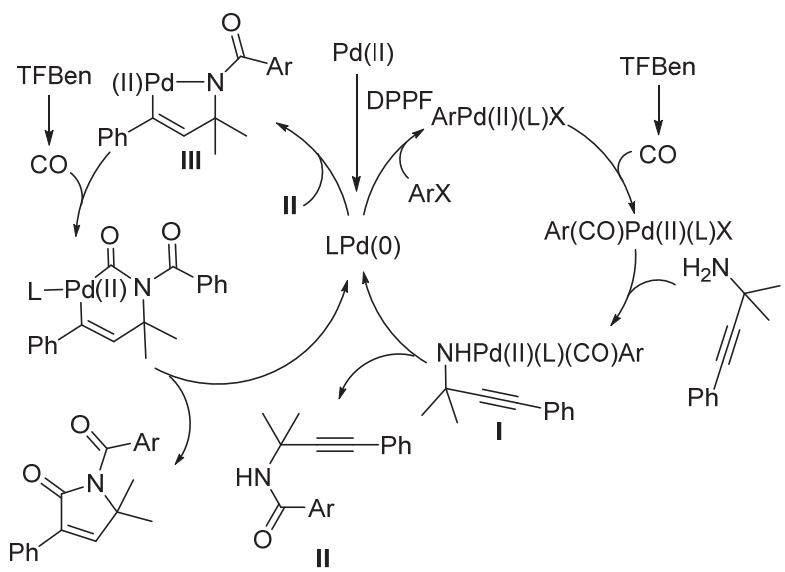

图式 6 合成芳甲酰基吡咯酮可能的反应机理

Scheme 6 Possible reaction mechanism for synthesis of aroyl pyrrolidone

1983 年, Orlinski 等 ${ }^{[38]}$ 首次以芳甲酸酐和缺电子取 代的烯烃为原料合成芳甲酰基取代的腈、醛、酮等化合 物, 该反应以维生素 $\mathrm{B}_{12}$ 或者钴为催化剂, 在光催化条 件下进行. 2014 年, Yamaguchi等 ${ }^{[39]}$ 报道了二环[2.2.1]庚2,5-二烯和芳甲酸酐在 $\operatorname{Pd}(\mathrm{dba})_{3}$ 催化条件下通过反式加 成得到芳甲酰基取代的化合物，反应收率为 34\% 79\%, 反应具有较好选择性(Eq. 15).

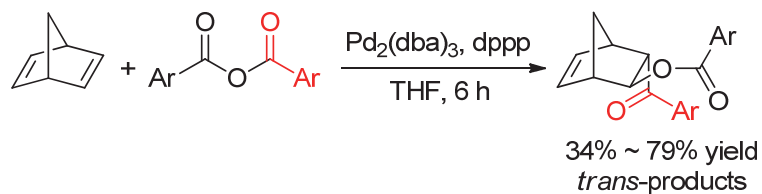

2015 年, $\mathrm{Ji}$ 等 ${ }^{[40]}$ 报道了一种以甲酸苯酯为羰基源, 制备芳甲酰基取代的 1,3-(2H)-狮二酮的方法，该反应以 2-碘代芳基- $\beta$-二酮为原料, $\mathrm{PdCl}_{2}(\mathrm{MeCN})$ 为催化剂, 磷 酸钾为碱性, $N, N-$ 二甲基亚砜为溶剂, 以中等到良好的 收率制得 2-芳基取代的 1,3-(2H)-狮二酮类化合物(Eq. 
16).

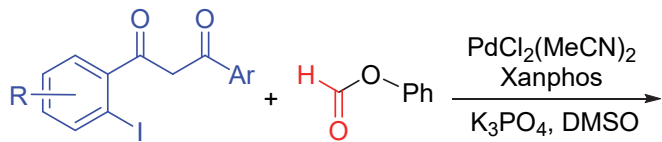
$\mathrm{Ar}=\mathrm{Ph}$, Furyl, Thienyl

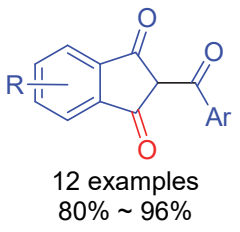

2018 年, 吴小峰课题组 ${ }^{[41]}$ 报道了甲酸 ${ }^{[42]}$ 作为羰基 源合成芳甲酰类化合物(芳基醛、酮等), 在一定程度上 替代了多聚甲醛或一氧化碳等羰基源的使用. 2020 年, 该课题组 ${ }^{[43]}$ 首次报道了以甲酸过氧化物为羰基源, 芳 基联烯和碘代芳烃为原料, 以氯化钯为催化剂, 在 $N, N$ 二甲基甲酰胺溶液中选择性合成了含 $\alpha$-支链烯酮类化 合物，收率达 76\%. 他们认为该反应收率一般的原因可 能与一氧化碳反应溶剂 DMSO 中的溶解度有关(Eq. 17).

$$
\begin{aligned}
& \text { : }-\mathrm{Ar}-\mathrm{I}+\mathrm{HCOOH} \underset{[\mathrm{CO}], \mathrm{DMSO}_{2}, \mathrm{BuPAd}_{2}, \mathrm{Et}_{3} \mathrm{~N}}{\longrightarrow} \\
& \mathrm{R}=\mathrm{Cl}, \mathrm{OMe} \text {, Alkyl } \\
& {[\mathrm{CO}]=\mathrm{AcOOCH}+\mathrm{Et}_{3} \mathrm{~N}} \\
& \begin{array}{c}
18 \text { examples } \\
\text { up to } 76 \% \text { yield }
\end{array}
\end{aligned}
$$

2020 年, Saito 等 ${ }^{[44]}$ 报道了在 $\mathrm{Pd}\left(\mathrm{PPh}_{3}\right)_{4}$ 的催化作用 下，芳甲酰氯与芳基锡烷的交叉偶联合成芳甲酰基类化 合物的方法，该反应速率快，收率达 $84 \%$ (Eq. 18).

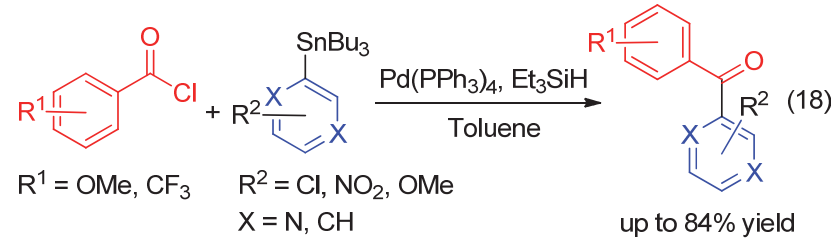

2020 年, 徐同玉等 ${ }^{[45]}$ 开发了在 $\operatorname{Pd}\left(\mathrm{PPh}_{3}\right)_{4}$ 催化条件 下，1-吡啶-1-苯丙炔新戊酸酯类化合物和芳基甲酰氯合 成 3-芳甲酰基吡啶并吡咯的方法, 该方法以三乙胺为 碱, 四氢呋喃为溶剂, 收率为 $51 \%$ \%9\% (Eq. 19).

他们认为该反应主要经历了以下几个历程(Scheme 7): 首先, 零价钯与芳甲酰氯经氧化加成得到 $\mathrm{ArCO}-$ $\mathrm{Pd}(\mathrm{II}) \mathrm{Cl}$, 然后与 1-吡啶-1-苯丙炔新戊酸酯作用得到络 合物 II, 最后在碱性条件下经脱盐酸、还原消除等步骤 得到目标化合物。
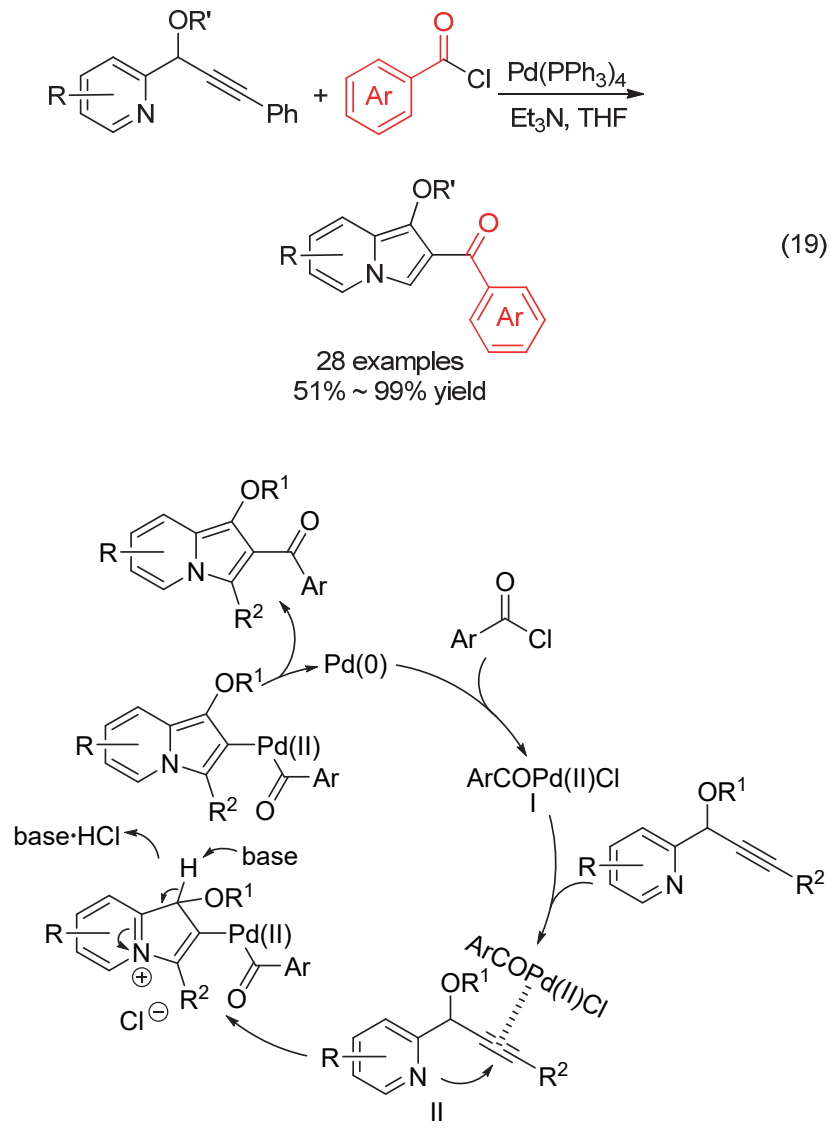

图式 7 合成 3-芳甲酰基吡啶并吡咯可能的反应机理 Scheme 7 Possible reaction mechanism for the synthesis of 3aroylpyridopyrroles

2019 年, 翁意意等 ${ }^{[46]}$ 报道了 3 -氧基香豆素和苯硼 酸在醋酸钯 $\left(\mathrm{Pd}(\mathrm{OAc})_{2}\right)$ 催化作用下，以水作为溶剂合成 3-芳甲酰基取代的香豆素方法，收率达 96\%. 在该反应 中，水除了作为溶剂以外，还提供了羰基氧原子，该方 法高效、绿色, 为香豆素的衍生化提供了重要的思路 (Eq. 20).

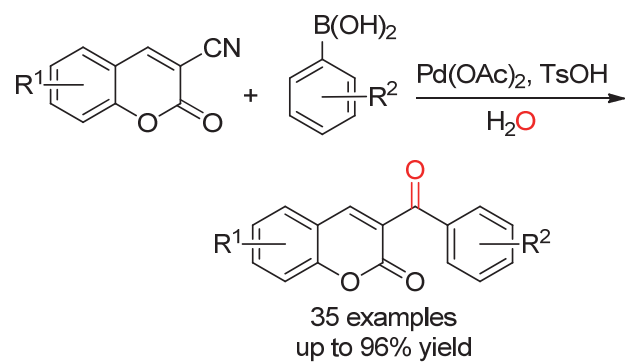

2020 年，陈久喜 ${ }^{[47]}$ 设计了 2-(2-甲酰基苯氧基)乙腈 类化合物与芳基硼酸在钯催化条件下合成 2-芳甲酰基 苯并呋喃衍生物的新方法，在该反应中，氧基碳和水分 子中氧为羰基源. 反应底物适用性广, 几乎实现完全转 化(Eq. 21). 


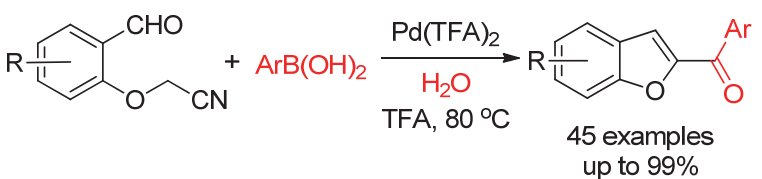

他们认为该反应按如下机理进行(Scheme 8): 首先 芳基硼酸与钯形成复合物 I, 复合物 I 与 2-(2-甲酰基苯 氧基)乙腈络合得到中间体 II; 然后中间体 II 发生重排 形成 II', II'进一步在酸性条件下形成亚胺中间体 III，亚 胺中间体 III 再水解得到中间体 IV; 最后, 中间体 IV 在 酸性条件下环合、芳构化脱水得目标产物.

\section{2 其他过渡金属为催化剂}

2013 年, Beller 等 ${ }^{[48]}$ 以芳基碘苯和含氮杂环取代的 芳烃为原料, $\mathrm{Ru}(\mathrm{COD}) \mathrm{Cl}_{2}$ 为催化剂, $\mathrm{KOAc} / \mathrm{NaHCO}_{3}$ 为 碱, 水为溶剂, 在一氧化碳氛围下合成了芳甲酰基类化 合物, 收率达 $75 \%$ (Eq. 22). 在该反应中, 含氮杂环作为 芳甲酰基化反应的定位基团.

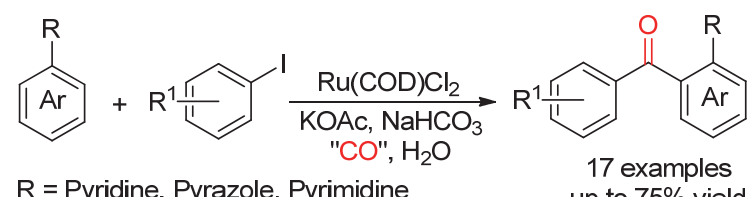

2021 年, 包明课题组 ${ }^{[49]}$ 以 $\left[\mathrm{Ru}(p \text {-cymene }) \mathrm{Cl}_{2}\right]_{2}$ 为催 化剂, $\mathrm{P}(p-\mathrm{Tol})_{3}$ 为配体, $2,4,6$-三异丙基苯甲酸(TIPBA)为 添加剂, $\mathrm{K}_{2} \mathrm{CO}_{3}$ 为碱, $N, N$-二取代的苯甲酰胺和 2-芳基吡 啶为原料, 经碳氢活化反应开发了芳甲酰基化取代的吡 啶类化合物的新方法, 收率达 84\% (Eq. 23).

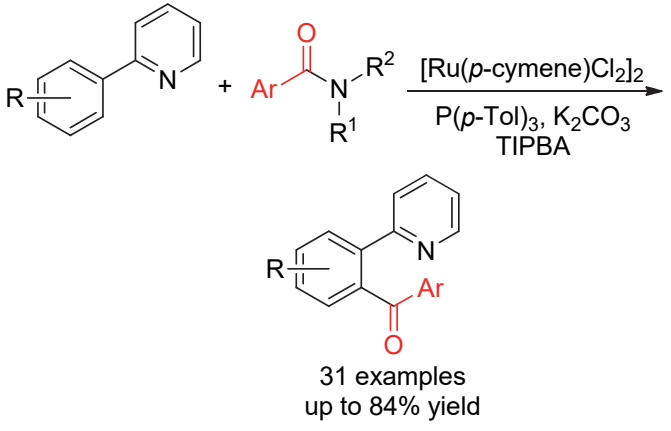

他们提出了如下的反应机理(Scheme 9): 首先, 钌 催化剂在 TIPBA 和 $\mathrm{K}_{2} \mathrm{CO}_{3}$ 的作用下形成络合物 $\mathbf{I}$, 然后 与 2-芳基吡啶形成中间体 II, II 进一步与 $\mathrm{P}(p-\mathrm{Tol})_{3}$ 和 2芳基吡啶得到配合物 III, III 再与 $N, N$-二取代的苯甲酰 胺类化合物反应得到中间体 IV; 最后，中间体 IV 在 TIPBA 作用下得到目标产物.

2016 年，罗来春等 ${ }^{[50]}$ 开发了一种新型的合成 3-芳 甲酰基取代的喹啉衍生物的方法. 该方法以邻氨基芳基 酮和芳基烯胺酮为原料，以 1,4-二氧六环为溶剂，在 $\mathrm{ZnCl}_{2}$ 催化条件下, 经 Friedländer 缩合得 3-芳甲酰基取 代的喹啉衍生物, 收率为 $42 \% \sim 87 \%$ (Eq. 24).

2018 年, Rueping 等[51]报道了一种以芳甲酸苯酯为 羰基源，硼烷为原料，在 $\mathrm{Ni}(\operatorname{cod})_{2}$ 的催化条件下通过配 体调控选择性合成芳甲酰基类化合物的方法. 该研究结 果显示，当以 $\mathrm{PBu}_{3}$ 或 $\mathrm{PCy}_{3}$ 为配体时，反应产物为芳甲 酰基类化合物; 然而，当以 Dcype 为配体时，反应产物 为烷基化化合物(Eq. 25).

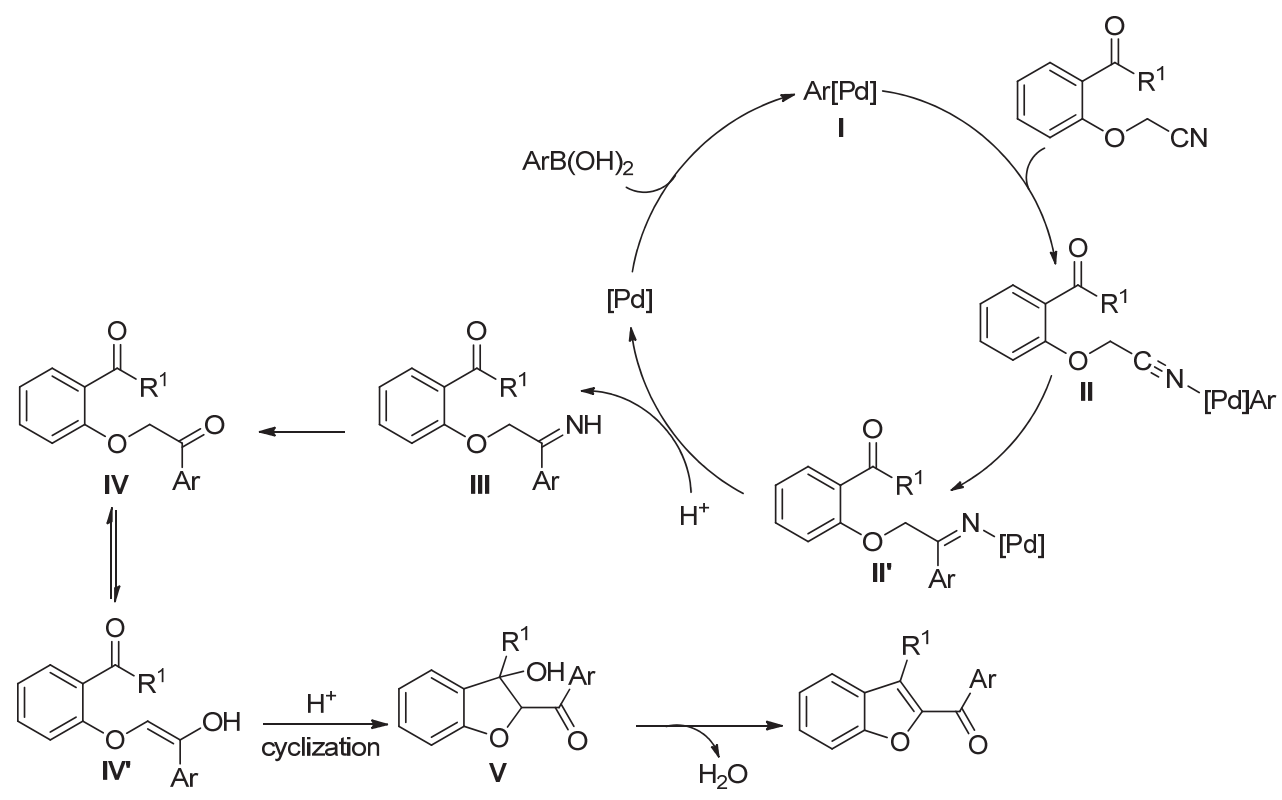

图式 8 合成 2-芳甲酰基苯并呋喃可能的反应机理

Scheme 8 Possible reaction mechanism for the synthesis of 2-aroyl benzofurans 


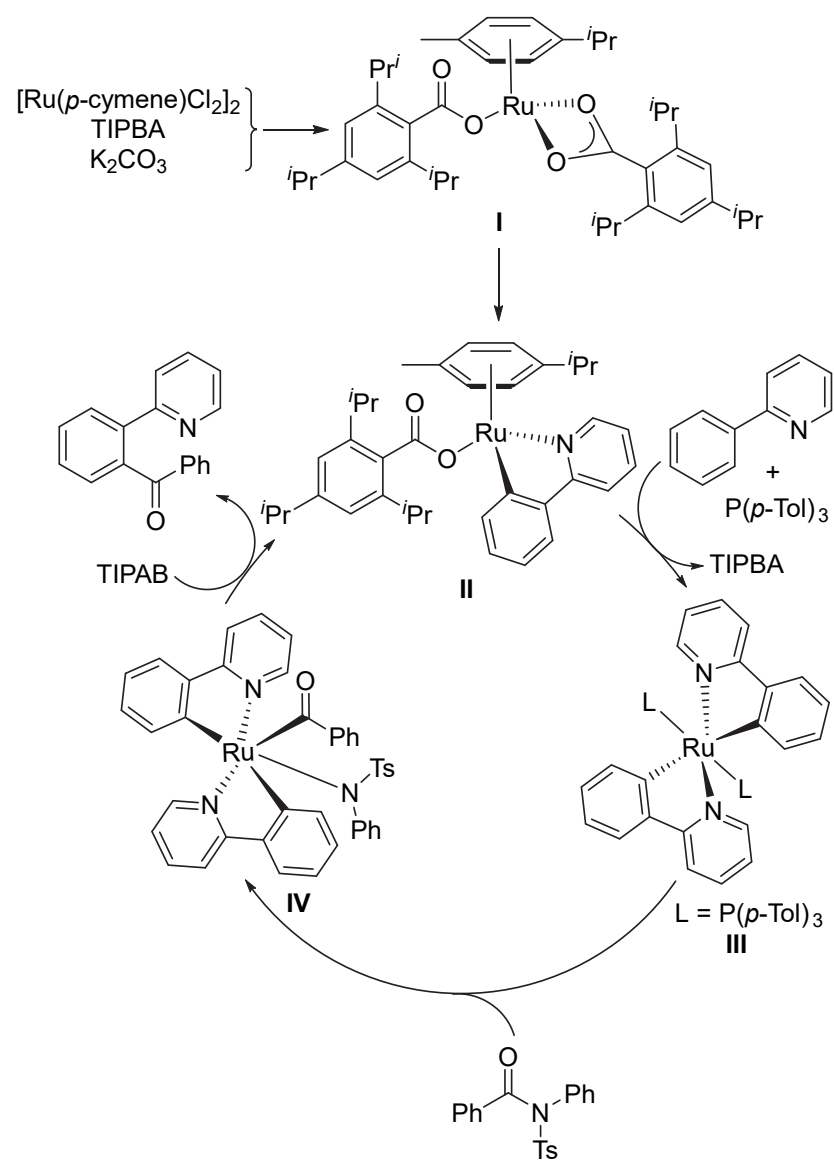

图式 9 2-芳基吡啶的芳甲酰基化反应可能的反应机理

Scheme 9 Possible reaction mechanism of the aromatic acylation of 2-arylpyridine

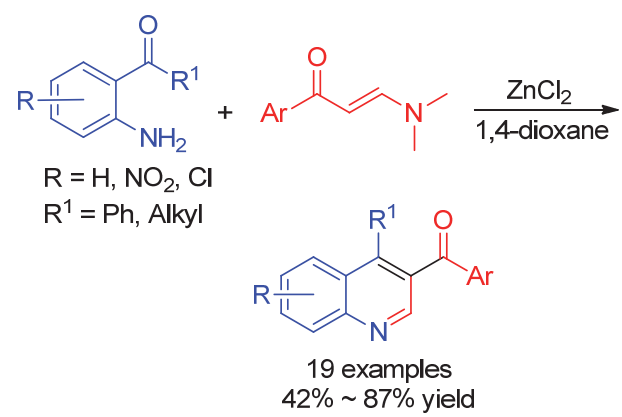<smiles>[R]CCB1C2CCCC1N(O[R16](=O)[OH2+])CCC2</smiles>

$\mathrm{R}=\mathrm{Ar}, \mathrm{CH}_{2} \mathrm{PMP}$<smiles>[R]CCC(=O)c1ccc2c(c1)CCCC2</smiles>

34 examples $64 \% \sim 91 \%$ yield

2020 年, Liu 等 ${ }^{[52]}$ 以碘代芳烃为原料, 以水合三氯
化铑为催化剂, 三苯基膦为配体, 三乙胺为碱, 在氢气/ 一氧化碳 $(0.5 \mathrm{MPa} / 0.5 \mathrm{MPa})$ 中合成了芳基甲醛类化合 物，收率为 $60 \% \sim 93 \%$. 该方法反应条件相对温和，适 用于各种芳基甲醛类化合物的制备，反应放大到克规模 级时, 收率稳定(Eq. 26).

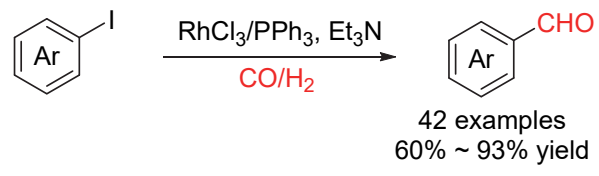

该反应的机理主要涉及到 $\mathrm{ArCOX}$ 的形成和还原等 过程, 如 Scheme 10 所示, 首先, 碘代芳烃和 $\mathrm{Rh}\left(\mathrm{PPh}_{3}\right)_{3}-$ $\mathrm{Cl}$ 在一氧化碳作用下得到中间体 $\mathrm{ArCORhLX}$; 然后，该 中间体在氢气条件下还原得到目标产物; 最后 HRhI$\left(\mathrm{PPh}_{3}\right)_{3} \mathrm{Cl}$ 在三乙胺作用下实现循环.

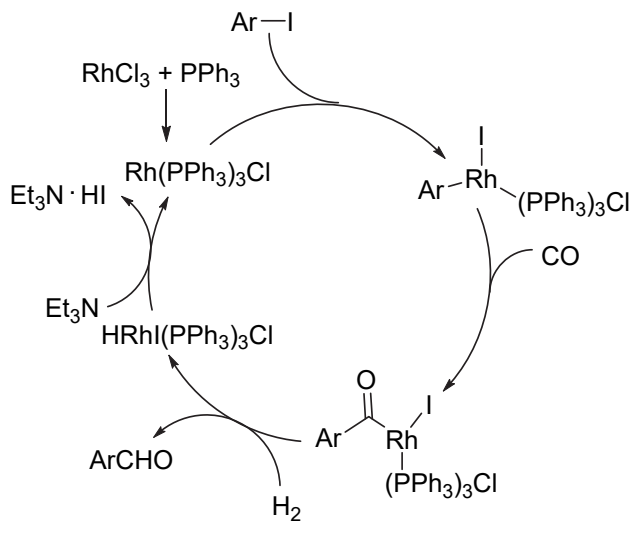

图式 10 铑催化合成芳基甲醛可能的反应机理

Scheme 10 Possible reaction mechanism for rhodium catalyzed synthesis of aryl formaldehyde

2020 年, $\mathrm{Li}$ 等 ${ }^{[53]}$ 以芳甲酸过氧化物为芳甲酰试剂, 在 $\mathrm{Co}(\mathrm{OAc})_{2}$ 条件下经 $\mathrm{C}-\mathrm{N}$ 偶联反应合成了大量的芳 基酰胺类化合物, 该反应不需要额外的碱或氧化剂的参 与, 反应条件温和，几乎无 $\mathrm{N}-\mathrm{O}$ 耦合产物，选择性好， 适用于芳甲酰基取代芳酰胺和脂肪酰胺类化合物的合 成(Eq. 27).

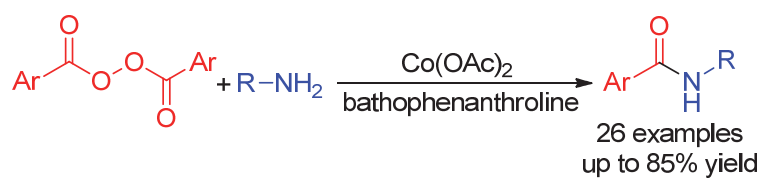

近年来, 以铜为催化剂, $\alpha, \beta$-不饱和酮作为芳甲酰 基源合成芳甲基取代的杂环类化合物得到了巨大的发 展. 2014 年 Kamarul 等 ${ }^{[54]}$ 报道了在氧气氛围中, 以 2-氨 基吡啶和 $\alpha, \beta$-不饱和酮为起始原料, 铜为催化剂, 合成 芳甲基取代的吡啶并咪唑衍生物的方法. 2015 年 Kumar 等 ${ }^{[55]}$ 以芳乙酮、醛、2-氨基吡啶类化合物为底物, $\mathrm{CuCl}_{2}$ 
为催化剂, $\mathrm{K}_{2} \mathrm{CO}_{3}$ 为碱, 在 DMF 中通过一锅法得到了芳 甲基取代的吡啶并咪唑衍生物. 随后大量研究人员对该 方法进行了改进(Eq. 28).<smiles>[R17]C(=O)c1c([Al])nc2ccc[R1]n12</smiles>

2017 年, 崔冬梅课题组 ${ }^{[56]}$ 以氨基三嗪为底物, $\alpha, \beta$ 不饱和酮为芳甲酰基源, 以铜为催化剂, $N, N^{\prime}$-二甲基乙 二胺(DMEDA)为配体, 开发了合成芳甲酰基取代的三 嗪并咪唑衍生物, 该反应具有较好的区域选择性, 收率 为 $61 \% \sim 96 \%$ (Eq. 29).

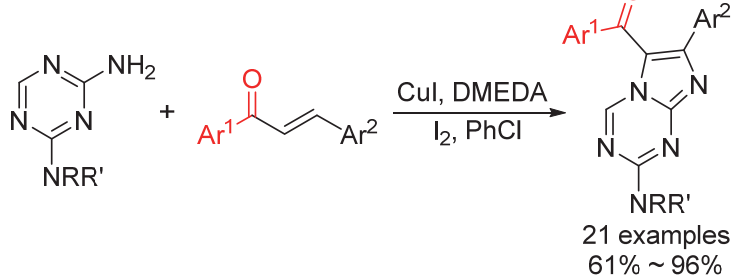

他们提出了如下反应机理(Scheme 11): 首先, 氨基 三嗪与 $\alpha, \beta$-不饱和酮发生迈克尔加成反应生成中间体 $\mathbf{I}$, 中间体 I 在碘单质作用下形成中间体 II; 然后中间体 II 与二价铜离子络合得到中间体 III, 中间体 III 在酸性条 件下转化为中间体 IV; 最后, 中间体 IV 发生还原消除 反应得到 $\mathbf{V}$. 另一方面, 中间体 II 在碱性条件下脱去一 分子碘化氢得到中间体 $\mathbf{V}, \mathrm{V}$ 在相同条件下发生快速
的芳构化得到目标产物 VI.

\section{2 通过自由基机理的反应}

\section{1 过渡金属参与的自由基反应}

2015 年, Patel 研究团队 ${ }^{[57]}$ 以吡啶为导向基团，茮溴 为芳甲酰基碳源, $\mathrm{Pd}(\mathrm{OAc})_{2}$ 为催化剂, 叔丁基过氧化氢 (TBHP)或 $N$-甲基氧化吗啉(NMO)为氧化剂, 开发了 2芳甲酰基取代的吡啶衍生物的合成方法，底物适用范围 广，收率为 $41 \% \sim 87 \%$ (Eq. 30).

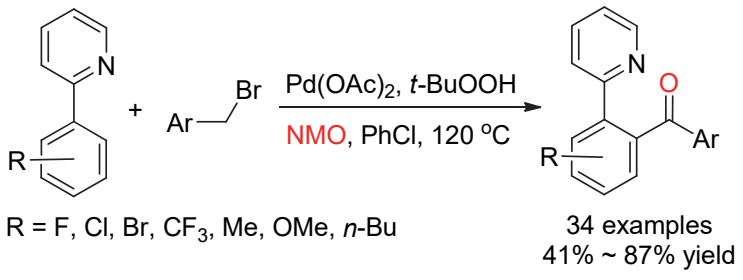

他们认为该反应是通过自由基机理进行的(Scheme 12): 首先，芳甲基溴在 $N$-甲基氧化吗啉(NMO)作用下 转化为芳基甲醛; 然后，芳基甲醛在过氧化叔丁醇作用 下形成芳甲酰基自由基; 最后，该自由基与钯(III)和 2芳基吡啶配合物经配位、消除等过程得到目标产物.

2017 年, Chakraborti 等 ${ }^{[58]}$ 对上述方法进行了改进, 对底物的适用性进行了进一步拓展. 他们以苯并噻唑、 吡啶、嘧啶、苯并噁唑等为导向基团, 以 $\mathrm{Pd}(\mathrm{OAc})_{2}$ 为催 化剂, 氧气为氧化剂, 甲基芳烃为碳源, 经 $\mathrm{C}-\mathrm{H}$ 活化、 氧化、亲核加成、还原消除等步骤构建芳甲酰基类化合

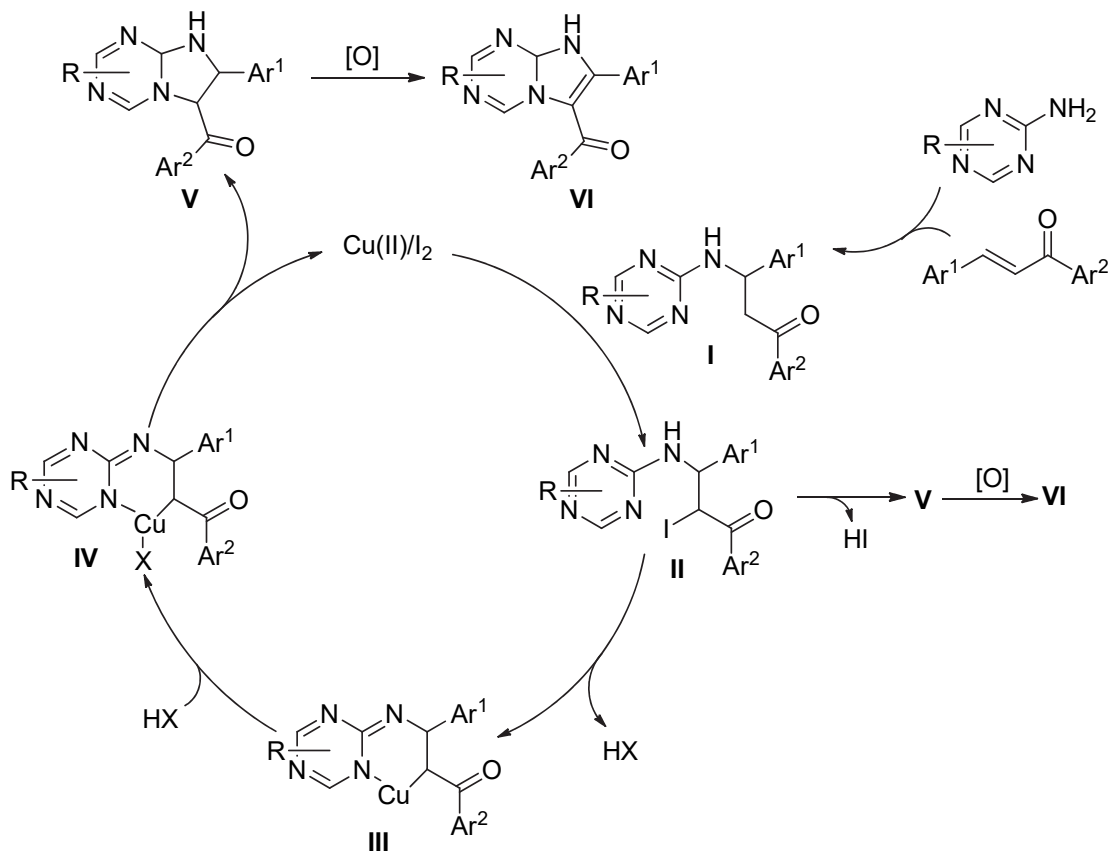

图式 11 铜催化合成 2-芳甲酰基取代的三嗪并咪唑可能的反应机理

Scheme 11 Possible mechanism for copper catalyzed synthesis of 2-aroyl substituted triazinoimidazoles 


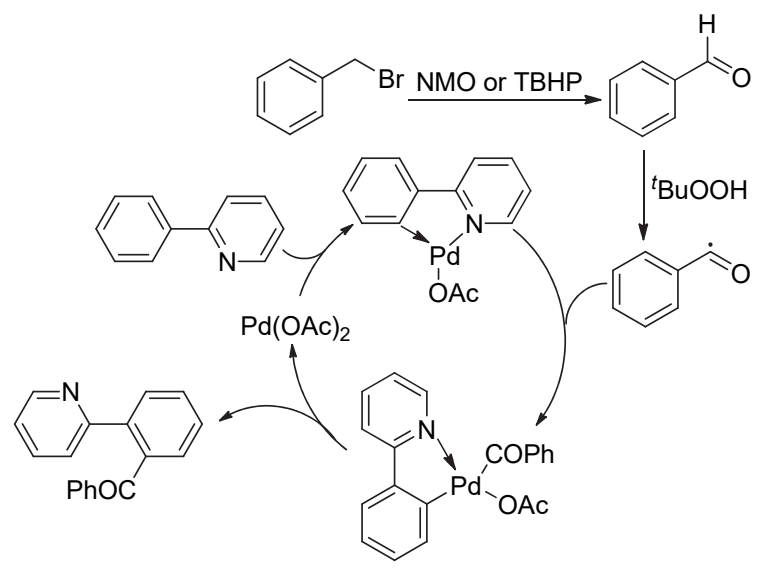

图式 12 钯催化 2-芳基吡啶的芳甲酰基化反应可能的反应机 理

Scheme 12 Possible reaction mechanism for palladium catalyzed aromatic acylation of 2-arylpyridine

物的方法, 收率为 $53 \%$ ～76\%. 该方法避免了对苄澳等 溴化物的使用. 他们认为该反应机理与 Patel 的报道 ${ }^{[57]}$ 类似, 也是通过自由基反应机理进行的, 甲苯在 $\mathrm{O}_{2}$ 和 $N$-差基邻苯二甲酰亚胺(NHPI) 条件下转化为芳甲酰基 自由基的反应是该反应的决定性步骤(Eq. 31).

$$
\mathrm{DG}=\text { benzothiazole, pyridine, etc. }_{53 \% \sim 76 \% \text { yield }}^{\mathrm{Ag}}+\mathrm{Ar}-\mathrm{CH}_{3} \frac{\mathrm{Pd}(\mathrm{OAc})_{2}}{\mathrm{O}_{2}, \mathrm{NHPI}}
$$

2018 年, 傅尧课题组 ${ }^{[59]}$ 报道了在蓝光环境下, 在 $\mathrm{Pd}(\mathrm{PhCN})_{2} \mathrm{Cl}_{2} /$ Xantphos 催化体系中, 以卤代芳烃为原 料, 乙醛酸为羰基源, 合成了一系列的芳基甲醛类化合 物, 他们认为该反应是通过单电子转移自由基机理进行 的. 2020 年, $\mathrm{Xu}$ 等 ${ }^{[60]}$ 报道了卤代芳烃在二(三苯基膦)二 氯化钯作用下, 在氧气氛围中以三乙胺为碱, 以偶氮二 异丁腈为自由基引发剂, 乙醛酸为羰基源合成了大量芳 基甲醛类化合物. 该反应机理与 $\mathrm{Liu}$ 等的报道有所不同, 他们认为该反应以自由基机理进行的，其中甲醛自由基 的形成是该反应发生的关键过程(Eq. 32).

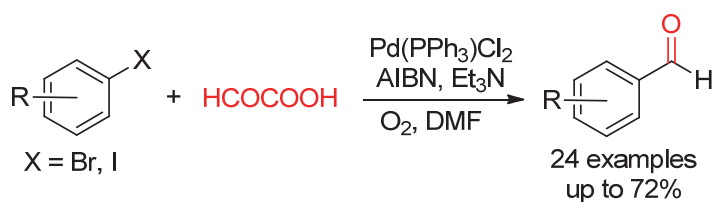

2014 年, Patel 等 ${ }^{[61]}$ 以 $\mathrm{Pd}(\mathrm{OAc})_{2}$ 为催化剂, 过氧化叔 丁醇为氧化剂, 芳基乙烯或芳基乙炔和 2-苯基苯并噻唑 类化合物为原料经 $\mathrm{C}-\mathrm{C}$ 键的断裂、脱氢偶联等反应合 成芳甲酰基取代的苯并噻唑衍生物, 该反应中由过氧化 叔丁醇与芳乙烯共同提供羰基碳源，收率为 $46 \% \sim 88 \%$
(Eq. 33).

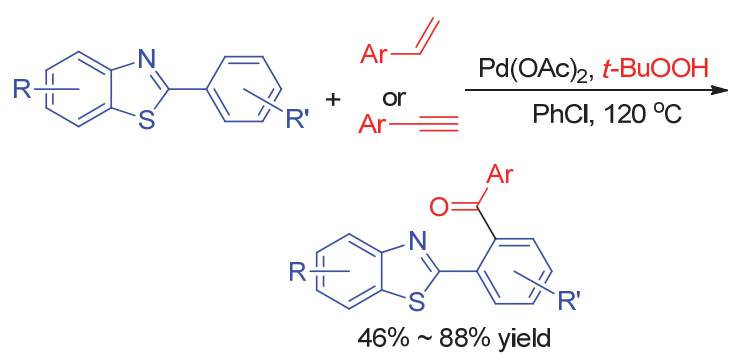

他们通过控制实验对该反应可能的机理进行了推 测(Scheme 13): 首先, 苯乙烯在钯(II)和过氧化叔丁醇 作用下形成含两个氧原子的四元环中间产物; 然后，该 中间产物开环得到 1-苯基乙二醇, 该醇被快速氧化为 1 苯甲酰基甲醛; 最后，1-苯甲酰基甲醛脱去一分子一氧 化碳得到苯甲醛，苯甲醛在 TBHP 作用下形成苯甲酰基 自由基，该自由基与钯(III)和 2-芳基噻唑类化合物经氧 化加成、还原消除等过程得到目标产物.
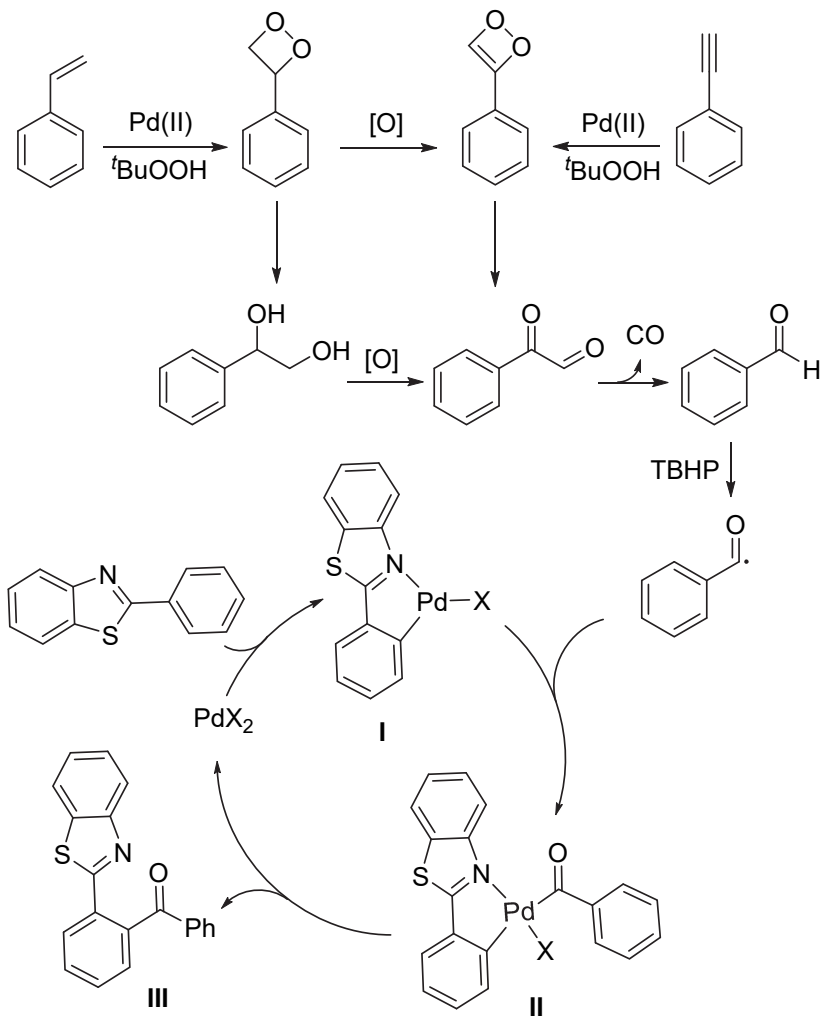

图式 13 钯催化 2-芳甲酰基取代苯并噻唑可能的反应机理 Scheme 13 Possible reaction mechanism for palladium catalyzed synthesis of 2-aroyl substituted benzothiazole derivatives

据大量文献报道，芳基甲酸、芳基酰卤、芳甲酸酐、 芳基酸酯、芳基酮酸等在过渡金属或光催化条件下经单 电子转移(SET)形成活化的芳甲酰基自由基的过程是该 类化合物转化为芳甲酰基类化合物重要的途径之一 ${ }^{[62]}$. 2015 年, Duan 等[63]以芳甲酮酸作为芳甲酰基化试剂合 
成 3,4-二芳甲酰基取代的香豆素、1,4-萗二酮、苯并吡 啶等, 该反应以 $\mathrm{AgNO}_{3}$ 为催化剂, $\mathrm{K}_{2} \mathrm{~S}_{2} \mathrm{O}_{8}$ 为氧化剂, 二 甲基亚砜(DMSO)和 $\mathrm{H}_{2} \mathrm{O}$ 混合溶液为溶剂, 收率达 $86 \%$ (Eq. 34). 屈凌波课题组 ${ }^{[64]}$ 对上述反应条件进行了改进, 他们以苯甲醛为芳甲酰基化试剂, 氯化亚铁为催化剂, 在叔丁基过氧化氢作用下合成了 3-芳甲酰基取代的香 豆素类化合物，收率为 38\% 72\%.

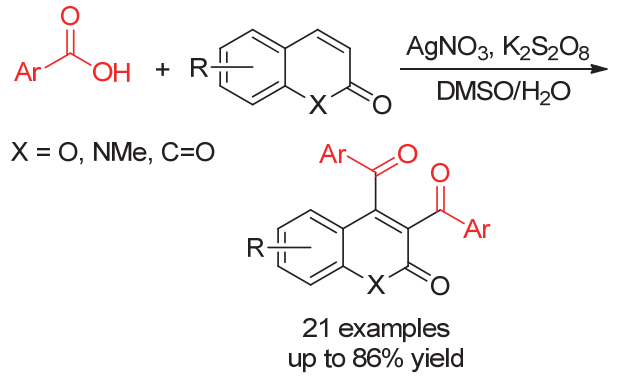

2017 年, Yotphan 等 ${ }^{[65]}$ 对反应适用性进行了改进, 他们以 $\mathrm{CuBr}$ 为催化剂, 芳基甲酩酸作为亚磺酰亚胺的 氮芳酰基化试剂, 该反应需添加 $\mathrm{K}_{2} \mathrm{~S}_{2} \mathrm{O}_{8}$ 作为氧化剂, 反 应较快, 平均反应时间在 $2 \mathrm{~h}$ 以内. 与甲酮酸直接相连 的取代基对该反应影响比较大, 当甲酮酸直接相连取代 为芳基类化合物，收率为 $25 \% \sim 91 \%$ ，然而，当底物为 烷基甲酮酸该反应几乎不发生. 他们认为该反应是按照 自由基机理进行的, 其中芳基甲酩酸在氧化剂和铜催化 剂作用下转化为苯甲酰基自由基是该反应顺利进行的 关键步骤(Eq. 35).

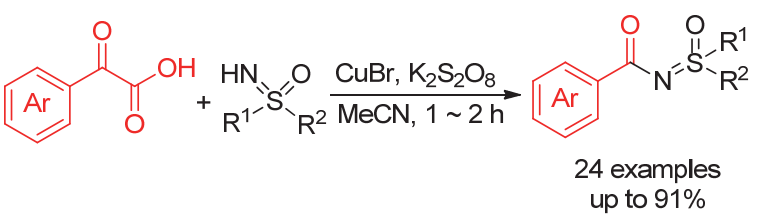

\section{2 可见光参与的自由基反应}

2015 年, 傅尧课题组 ${ }^{[66]}$ 报道了以芳基甲酮酸和 $\alpha, \beta-$ 不饱和酮为原料，在光催化下合成芳甲酰基类化合物的 方法. 该方法在 $36 \mathrm{~W}$ 蓝光氛围下进行的, 以 $\operatorname{Ir}\left[\mathrm{dF}\left(\mathrm{CF}_{3}\right)-\right.$ ppy $]_{2}$ (phen) ${ }^{+} \mathrm{PF}_{6}^{-}$为金属催化剂, $\mathrm{K}_{2} \mathrm{HPO}_{4}$ 为碱, 二氯甲 烷 $(\mathrm{DCM}) / \mathrm{H}_{2} \mathrm{O}(V: V=1: 1)$ 混合溶液为溶剂, 收率 $58 \% \sim 94 \%$ (Eq. 36).

他们推测该反应是按照自由基脱羧、亲核加成等过 程进行的(Scheme 14): 首先, 芳甲基酮酸在金属催化剂 作用下脱羧转化为苯甲酰基自由基，进一步与烯烃发生 加成得到中间体 $\mathbf{I}$; 然后, 中间体 $\mathbf{I}$ 被 $\mathrm{M}^{n^{-1}}$ 还原得到碳 负离子中间体 II ; 最后，中间体 II 在酸性条件下形成目 标化合物.

2017 年, Yang 等 ${ }^{[67]}$ 以芳甲酰氯和 $\alpha, \beta$-不饱和酮为原 料, $\left[\mathrm{fac}-\operatorname{Ir}(\mathrm{ppy})_{3}\right]$ 为催化剂, 在可见光催化下经 Michael
加成合成了芳甲酮类化合物，收率达 $89 \%$. 反应中额外 添加了还原剂 Hantzsch 酯及碱 $\mathrm{NaHCO}_{3}$ (Eq. 37).

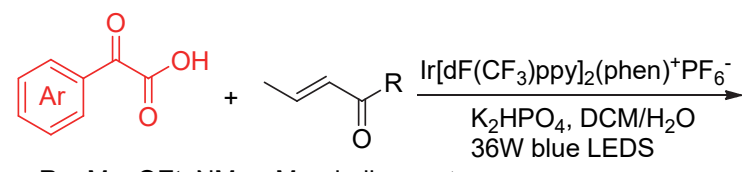

$\mathrm{R}=\mathrm{Me}, \mathrm{OEt}, \mathrm{NMe}_{2}$, Morpholine, ect. $36 \mathrm{~W}$ blue LEDS<smiles>[R]C(=O)CC(C)C(=O)c1ccccc1</smiles>

\section{0 examples} $58 \% \sim 94 \%$ yield
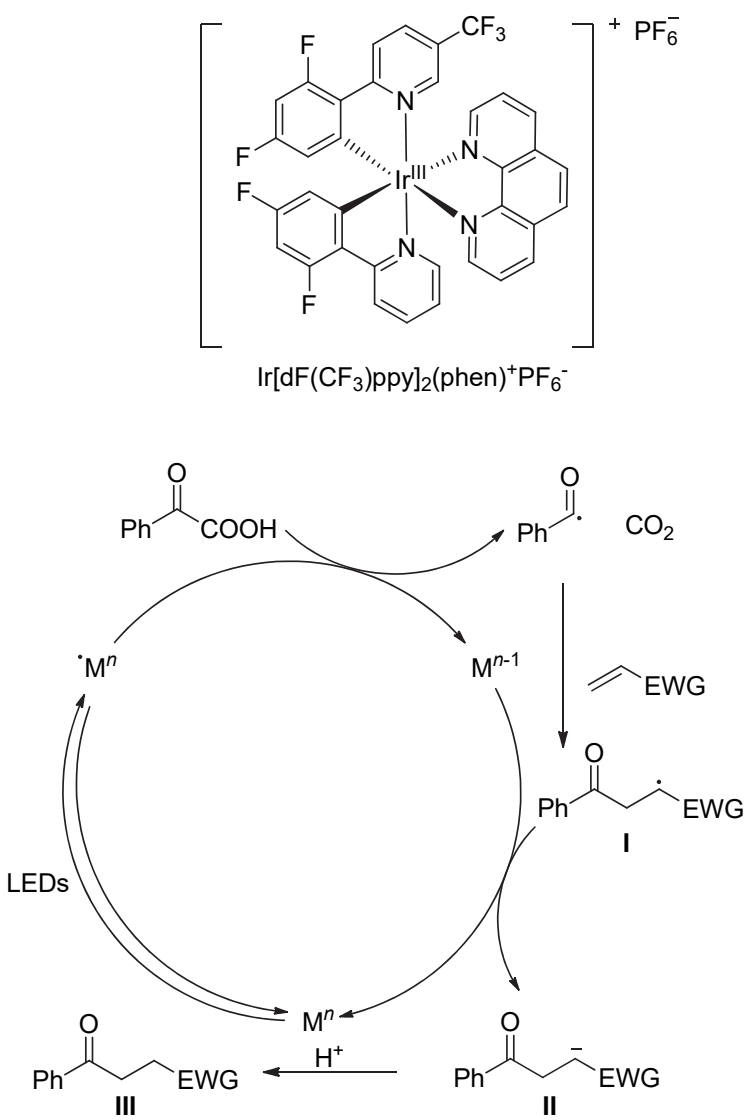

图式 14 光催化 $\alpha, \beta$-不饱和酮的芳甲酰基化反应可能的反应 机理

Scheme 14 Possible mechanism for photocatalytic aromatic acylation of $\alpha, \beta$-unsaturated ketones

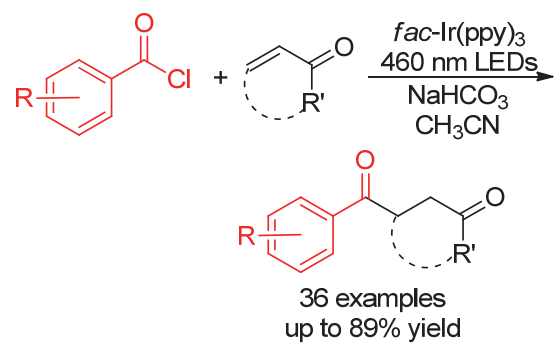

该反应是按单电子转移机理进行的(Scheme 15), 


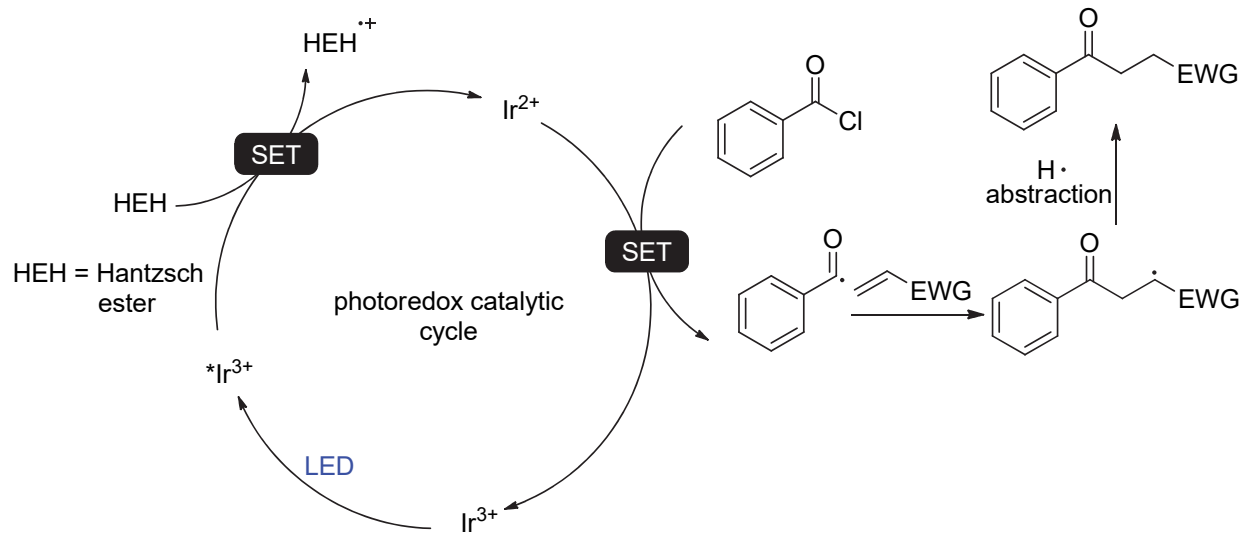

图式 15 光催化 $\alpha, \beta$-不饱和酮和芳甲酰氯的芳甲酰基化反应可能的反应机理

Scheme 15 Possible reaction mechanism for photocatalytic aromatic acylation of $\alpha, \beta$-unsaturated ketones with aroyl chloride

首先三价的铱催化剂在 $460 \mathrm{~nm}$ 的 LED 灯源下形成激发 态的* $\mathrm{Ir}^{3^{+}}$, 该激发态* $\mathrm{Ir}^{3^{+}}$在 Hantzsch 酯作用下被还原成 $\mathrm{Ir}^{2+}$; 然后, $\mathrm{Ir}^{2+}$ 与芳甲酰氯经单电子转移得到芳甲酰基 自由基; 最后, 芳甲酰基自由基与烯烃发生 Michael 加 成反应，进一步从二乙基-1,4-二氢-2,6-二甲基-3,5-吡啶 二羧酸酯 $(\mathrm{HEH})$ 自由基获得氢自由基形成目标产物.

2019 年, Ngai 等[68]报道了在光催化条件下，芳甲酰 氯选择性与活性烯烃经亲核加成、还原消除反应合成芳 甲酰基化的不饱和烯烃的方法. 该方法具有很高的化学 区域选择性，适用范围广泛，适合各种糖、多肽、天然 产物、核苷等的合成. 另外, 该反应中 2,6-二叔丁基-4甲基吡定添加剂不仅起到了碱的作用, 还促进了电子转 移，极大的提高了反应收率(Eq. 38).

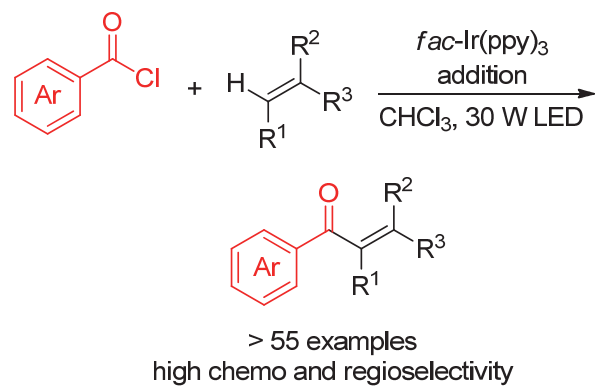

他们通过理论计算化学和控制实验对反应机理进 行了推测 (Scheme 16), 认为该反应是按照质子耦合电 子转移(PCET)和单电子转移(SET)机理进行的: 芳甲酰 氯在 2,6-二叔丁基-4-甲基吡啶和单电子 $\operatorname{Ir}(\mathrm{ppy})_{3}$ 作用下 发生质子耦合电子转移得到自由基 $\mathbf{I}$; 然后自由基 $\mathbf{I}$ 与 烯烃发生亲核加成得到自由基 II; 最后自由基 II 经氯原 子的迁移、单电子转移等过程得到 III, III 在反应后处 理过程中脱氯化氢得目标产物.

2020 年, Studer 等[69]在上述反应基础上, 以光(日光 灯 )/6,7-二氢-2-(2,4,6-三甲基) 苯基-5H-吡咯并 [2,1-c]1,2,4-三唑啉四氟硼酸盐(NHC)为催化剂, 芳甲酰氟和
芳乙烯为原料，在体系中加入 Langlois 试剂，通过自由 基反应一锅法合成了芳甲酰基、三氟甲基取代的芳烃类 化合物(Eq. 39).

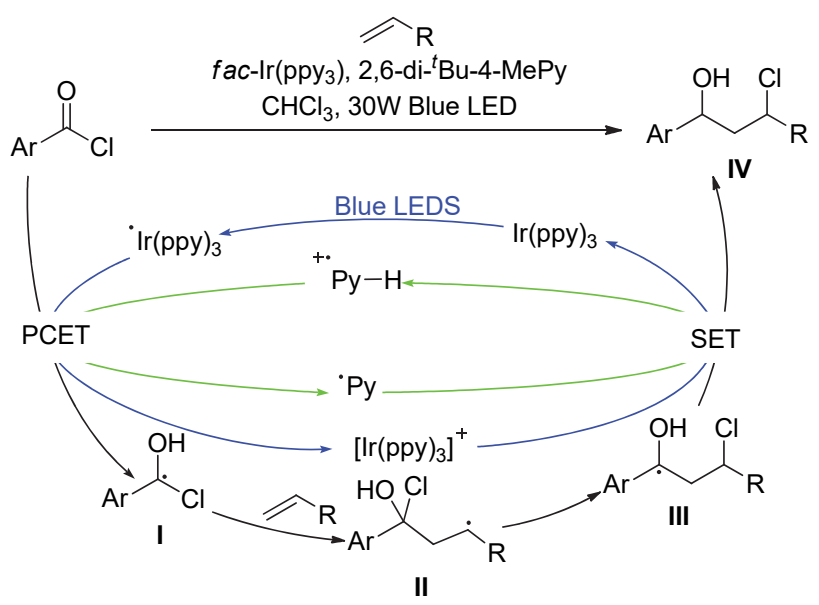

图式 16 光催化烯烃和芳甲酰氯的芳甲酰基化反应可能的反 应机理

Scheme 16 Possible reaction mechanism for photocatalytic aromatic acylation of alkenes with aroyl chloride

$$
\text { 等 }
$$

他们认为该反应通过单电子转移机理进行(Scheme 17). 一方面，苯甲酰氟与 NHC 结合形成苯甲酰基取代 


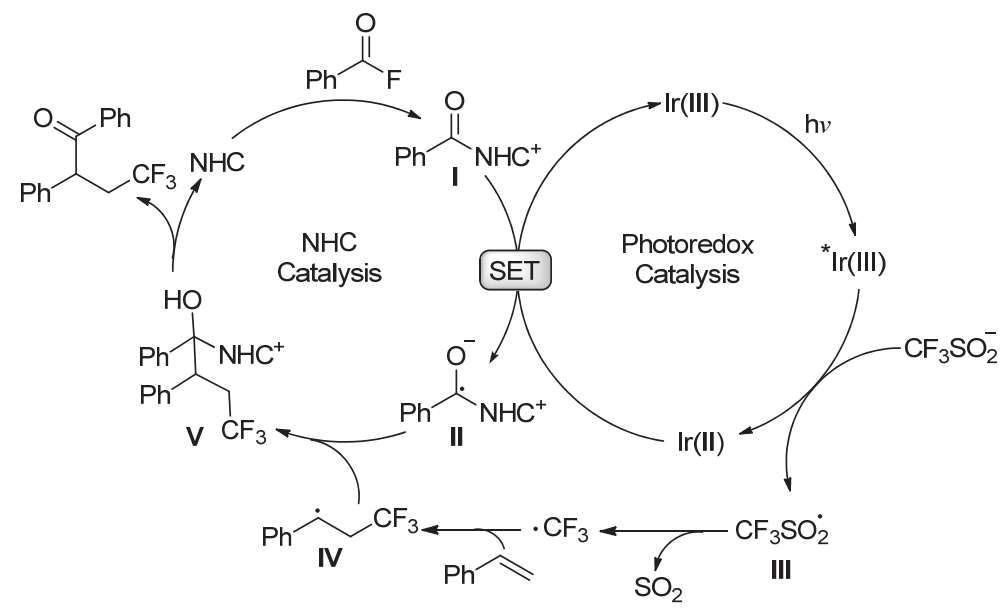

图式 17 光催化芳甲酰基氟作为酰基化试剂可能的反应机理

Scheme 17 Possible reaction mechanism for photocatalytic aroyl fluoride as acylation reagent

的 NHC 正离子 I, 然后通过单电子转移得到自由基 II, 另一方面, 二价的 $\operatorname{Ir}(\mathrm{II})$ 催化剂发生单电子转移形成三 价的 $\operatorname{Ir}(\mathrm{III})$ 催化剂; 然后, $\operatorname{Ir}(\mathrm{III})$ 在光催化作用下形成 Ir(III)自由基, 该自由基与三氟甲基亚磺酸离子反应得 到三氟甲基亚磺酸自由基 III, 三氟甲基亚磺酸自由基 经脱去 $\mathrm{SO}_{2}$ 后，与苯乙烯发生亲核加成反应得到自由基 IV; 最后, 自由基 IV 与中间体 II 作用得到化合物 $\mathrm{V}, \mathrm{V}$ 进一步脱氢得到目标化合物.

2015 年, Wallentin 等 ${ }^{\left[{ }^{70]}\right.}$ 开发了一种以芳基羧酸和烯 烃为起始原料, 在可见光催化条件下, 经串联酰基芳基 化反应合成芳甲酰基取代的苯并吡咯酮的方法, 该方法 条件温和, 操作简单, 收率达 $99 \%$. 该方法提供了一种 高效的芳甲酰基自由基产生体系, 有利于应用到 $\mathrm{C}-\mathrm{C}$ 键的耦合反应(Eq. 40).<smiles>C=C(C)C(=O)N(C)c1cccc([13CH]=C(C)C)c1</smiles><smiles>[R]c1ccccc1C(=O)CC1(O)C(=O)N(C[13C](=O)[O-])c2ccccc21</smiles>

他们认为酸酐是该反应中重要的中间体, 并对该反 应的机理进行了推测(Scheme 18): (1)首先, 芳甲酸与碳 酸二甲酯(DMDC)反应得到酸䣶, 酸酐在 $* \operatorname{Ir}(\mathrm{III})$ 作用下 脱羧得到芳甲酰基自由基; (2)芳甲酰基自由基与烯烃发 生亲核加成得到中间体 II; (3)最后, 中间体 II 迅速芳构
化得到目标化合物.

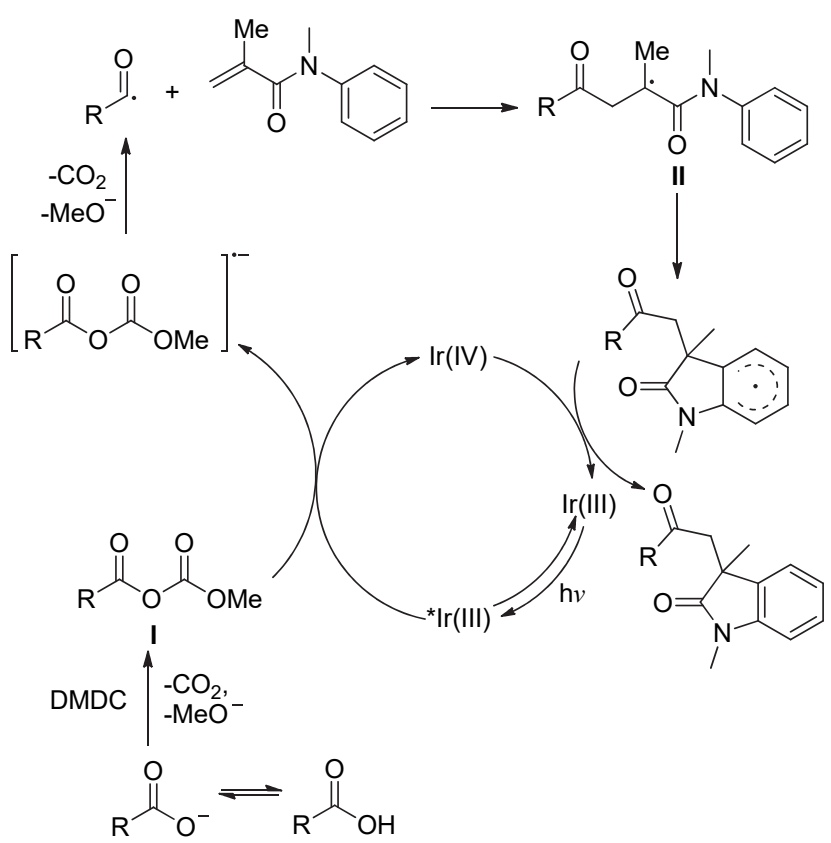

图式 18 光催化合成苯并吡咯酮可能的机理

Scheme 18 Possible mechanism for the photocatalytic synthesis of benzopyrrolone

2017 年, Ye 等 ${ }^{[71]}$ 在上述工作的基础上直接以芳甲 酸酕替代羧酸对反应进行了优化和底物适用性拓展, 在 该反应中, 需要添加额外的 $N, N$-二异丙基乙胺或 Hantzsch 酯作为还原剂参与铱催化剂的循环, $\mathrm{Xu}$ 等 ${ }^{[72]}$ 在金属铱配合物 $\left[f a c-\operatorname{Ir}(\mathrm{ppy})_{3}\right]$ 作用下，以蓝色 LED 灯源 为光氧化还原催化剂, 以苯甲酰氯替代羧酸和酸䣶, 开 发了合成芳甲酰基取代的苯并吡咯酮的合成方法，并对 反应机理进行了探讨. 他们认为该反应与上述机理类 似，也是通过自由基反应进行的，同时强调了苯甲酰自 由基是该反应最重要的中间过渡态之一。 
2015 年, 肖文精课题组和 Jacobi 等[73-74]在 Angew. Chem., Int. Ed. 上同时报道了合成芳酸酯的新方法. 他们 以芳基重氮盐替代卤代芳烃，将反应置于 LED 灯源下， 加入 $30 \% \sim 40 \%$ eosin $\mathrm{Y}$ 或 Fluorescein 作为电子转移介 质，在一氧化碳氛围下制得芳甲酸酯类化合物，该反应 温度可降至 $18{ }^{\circ} \mathrm{C}$ 下进行, 芳环上取代基对反应收率影 响不大. 2017 年, Jacobi 等[75]发现, 在无 LED 灯源条件 下，在反应体系中加入等物质的量的甲酸盐时, 将反应 混合物置于室温条件下，反应仍然可以发生(Eq. 41).
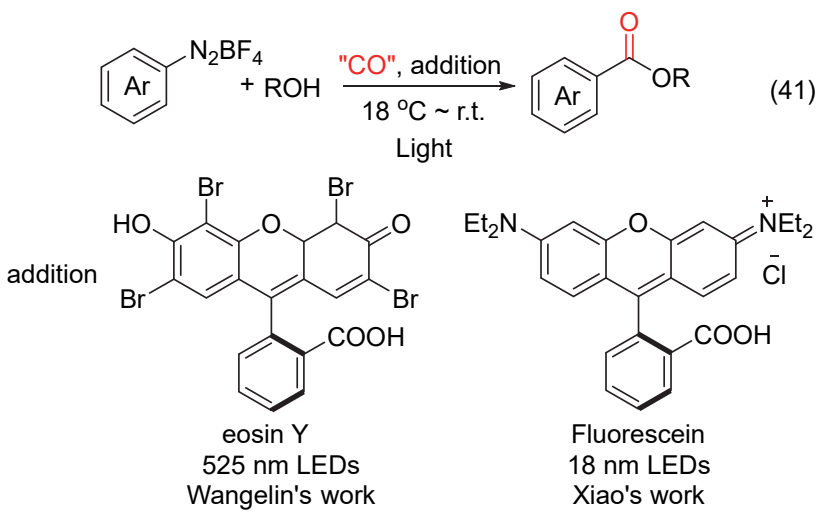

2021 年, 许鹏飞课题组 ${ }^{[76]}$ 首次报道了通过光催化 促进胺 $\left(\mathrm{sp}^{3}-\mathrm{H}\right)$ 的芳甲酰基化反应，该反应不需要过渡金 属的参与. 该反应以脂肪胺和芳甲酰氯为原料, $4 \mathrm{CzIPN}$ 为催化剂, 丙酸钠为碱, 二氯甲烷为溶剂, 在 $50 \mathrm{~W}$ 白光 条件下得到 $\alpha$-芳甲酰基取代的脂肪胺类化合物, 收率为 $40 \% \sim 97 \%$ (Eq. 42).

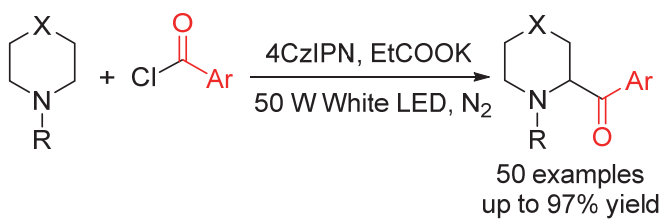

该反应主要经历以下几个过程(Scheme 19): (1)首先 $4 \mathrm{CzIPN}$ 在 $50 \mathrm{~W}$ LED 灯源条件下被激发形成其激发态 $* 4 \mathrm{CzIPN}$, 脂肪胺与* $4 \mathrm{CzIPN}$ 通过单电子转移反应形成 胺的自由基阳离子, 该自由基阳离子进一步在丙酸钾作 用下形成 $\alpha$-胺自由基; (2)然后 4CzIPN 负离子与芳甲酰 氯通过单电子转移反应得到芳甲酰氯自由基负离子，该 自由基负离子在相同条件下离去一分子氯离子得到芳 甲酰基自由基; (3)最后, 芳甲酰基自由基与 $\alpha$-胺自由基 经自由基-自由基偶联反应得到 $\alpha$-芳甲酰基取代的脂肪 胺类化合物.

2021 年, Zhu 等 ${ }^{[77]}$ 开发了一种无过渡金属催化条件 下，可见光促进芳甲酰基取代的杂环类化合物的合成新 方法. 该方法以芳基酮酸作为芳甲酰基试剂, 以 2,4,5,6-

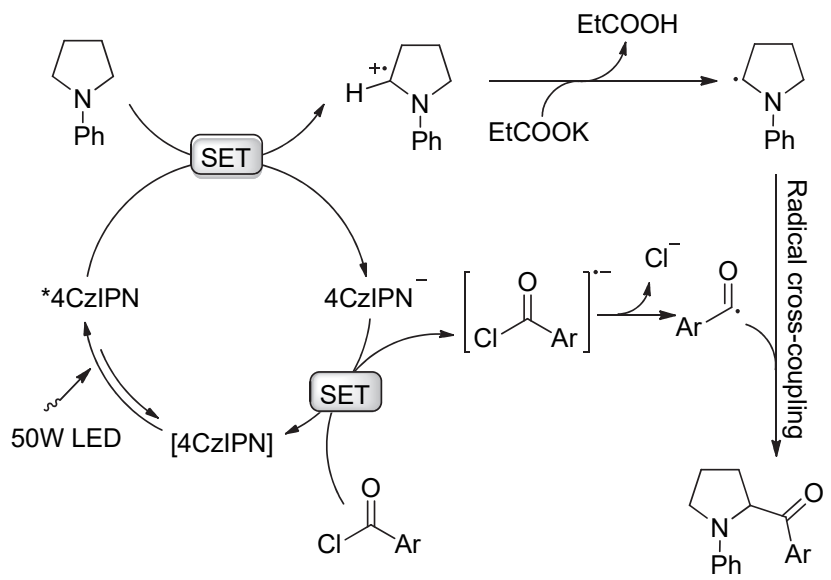

图式 19 光催化促进的胺 $\left(\mathrm{Sp}^{3}-\mathrm{H}\right)$ 的芳甲酰基化反应可能的机 理

Scheme 19 Possible mechanism for photocatalysis promotes the arylformylation of amines

四(9-咔唑基)间苯二腈(4CzIPN)为催化剂，在 LED (5 W) 蓝光, 空气氛围条件下进行。该反应以碳酸二甲酯 $(\mathrm{DMC})$ 为溶剂时, 适用于苯并咪唑/吲哚 $[2,1-a]$ 异喹啉$6(5 H)$-酮的合成，收率达 $88 \%$ ，当以乙腈作为溶剂，在 反应体系中添加过量的过氧二苯甲酰(BPO)时，适用于 芳基氮杂 [4.5] 三烯酮和芳甲酰基取代的硫代黄酮的合 成，收率达 80\% (Scheme 20)。

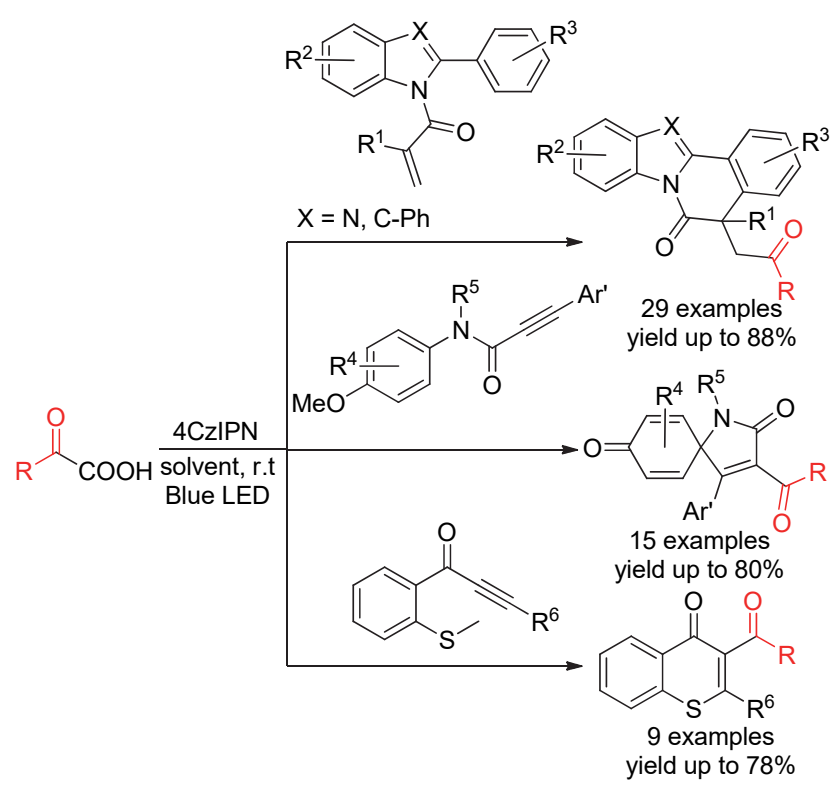

图式 20 可见光催化条件下芳基酮酸作为芳甲酰基化试剂

Scheme 20 Aryl keto acid as aroformylation reagent under visible light catalysis

\section{3 其他自由基反应}

2012 年，雷爱文课题组 ${ }^{[78]}$ 报道了在无过渡金属催 化和可见光条件下，以一氧化碳为羰基源，叔丁醇钾为 碱，将卤代芳烃转化为芳甲酸叔丁酯的新方法，底物适 
用性研究显示, 芳环上取代基电性对反应收率影响较 大, 当芳环上具有吸电子基( $\mathrm{Cl} 、 \mathrm{COOEt}$ 等)取代时, 收 率在 $60 \%$ 以下; 当芳环上为供电子基( $\mathrm{Me} 、 \mathrm{OMe} 、 \mathrm{Ph}$ 等) 取代时, 收率为 $60 \% \sim 81 \%$; 此外, 碘代芳烃和溴代芳 烃均适用于该反应. 他们通过电子顺磁共振(EPR)实验 证实了该反应是通过自由基机理进行的(Eq. 43).

$$
\begin{aligned}
& \underset{\mathrm{X}=\mathrm{I}, \mathrm{Br}}{\mathrm{X}}+t \text {-BuOK } \frac{\mathrm{CO} ", 1,10 \text {-phenanthroline }}{90^{\circ} \mathrm{C} \text {, benzene }} \\
& 36 \% \sim 81 \% \text { yield }
\end{aligned}
$$

2016 年, Abbasnia 等 ${ }^{[79]}$ 报道了以芳基醛或芳基醇作 为酰化试剂, 叔丁基过氧化氢(TBHP)为氧化剂, 开发了 一种高效的合成 3-芳甲酰基取代的香豆素的方法, 收率 达 $75 \%$. 该反应具有区域选择性高、底物适用范围广等 特点(Eq. 44).
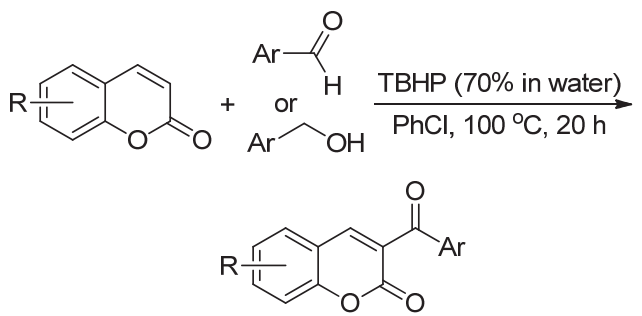

High regioselective up to $75 \%$ yield

Abbasnia 等[79]认为该反应机理如 Scheme 21 所示, 首先, 过氧叔丁醇在加热条件下转化为叔丁氧自由基和 羟基自由基, 芳基甲醛在叔丁氧自由基条件下转化为芳 甲酰基自由基; 然后, 芳甲酰基自由基与香豆素发生亲 核加成反应得到 3-芳甲酰基取代的香豆素自由基; 最 后，在羟基自由基作用下得到 3-芳甲酰基取代的香豆 素.

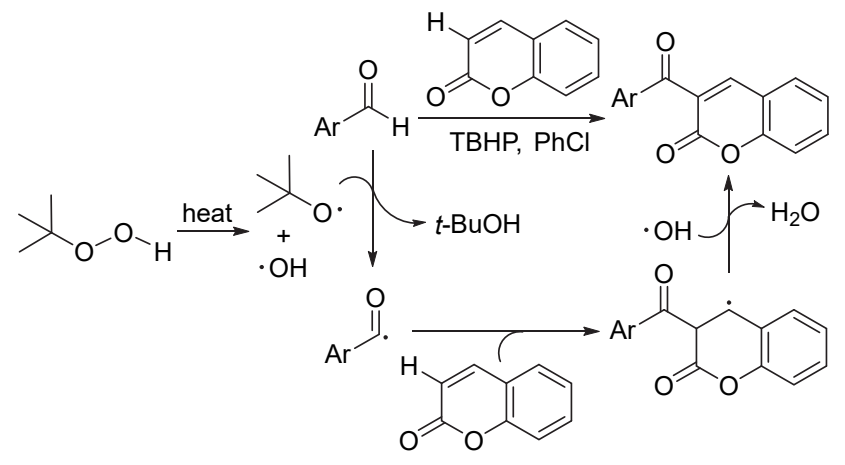

图式 21 香豆素的芳甲酰基化反应可能的机理

Scheme 21 Possible mechanism for aromatic acylation of coumarin

\section{3 通过其他机理的反应}

2018 年, Chandrasekhar 等 ${ }^{[80]}$ 报道了无过渡金属催 化条件下，2-(三甲基硅烷)三氟甲磺酸苯酯与芳乙酮基 锍溴化盐在 $N, N$-二甲基甲酰胺中通过一锅法 $[2+2]$ 偶联 和 $[4+1]$ 环合得到 2-芳甲酰基苯并呋喃的新方法, 其中 溶剂 $N, N$-二甲基甲酰胺在反应中为呋喃环的构建提供 碳源，该方法操作简单，底物适用性广泛，收率 35\% $87 \%$ (Eq. 45).

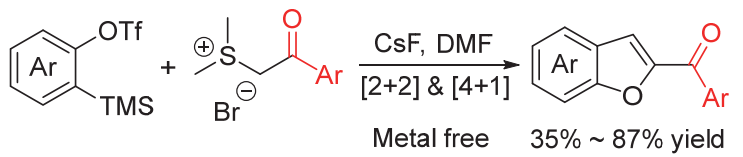

他们认为该反应可能按以下机理进行(Scheme 22), 首先 2-(三甲基硅烷)三氟甲磺酸苯酯在 $\mathrm{CsF}$ 作用下转化 为苯炔, 苯炔进一步与 DMF 加成形成 $\mathbf{I}$ 或 $\mathbf{I I}$; 然后该中 间体与芳乙酮基锍溴化盐发生 $[4+1]$ 环加成反应得到中 间体 III; 最后中间体 III 在 CsF 作用下发生芳构化得到 芳甲酰基苯并呋喃.

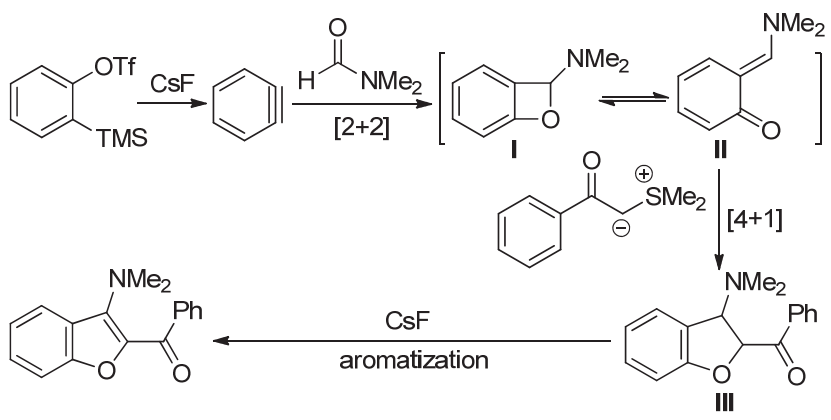

图式 $22[2+2]$ 偶联和 $[4+1]$ 反应合成 2-芳甲酰基苯并呋喃可 能的反应机理

Scheme 22 Possible mechanism for the synthesis of 2-aroyl benzofuran via $[2+2]$ coupling and $[4+1]$ cyclization

2020 年, 崔冬梅课题组 ${ }^{[81]}$ 在上述基础上将 $\alpha, \beta$-不饱 和酮改为 1,3-二酮类化合物，在无过渡金属催化条件下， 开发了三嗪并咪唑衍生物, 该反应需要添加等物质的量 的 $N$-溴代丁二酰亚胺(NBS)作为卤代试剂, 底物适用性 广泛，研究表明 $\beta$-酮酯、 $\beta$-酮酰胺也适用于该反应，收 率 40\% 93\% (Eq. 46).

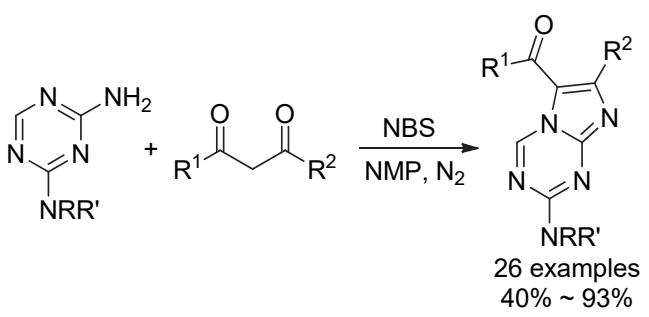

2018 年, Sen 等[82]报道了一种无金属催化条件下合 
成 2-芳甲酰基吲哚衍生物的方法. 1-芳基四氢-咔啉在碘 和过氧化氢作用下经氧化开环、水解等过程形成 2-芳甲 酰基吲哚衍生物, 收率为 $62 \% \sim 92 \%$. 该方法可以用于 克规模级的选择性裉黑激素受体拮抗剂 Luzindole 的制 备(Eq. 47).

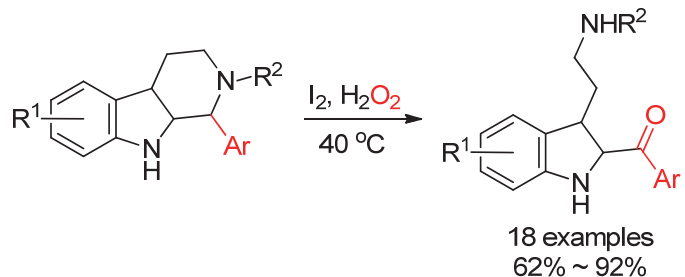

氧化芳环苄位的亚甲基是合成芳甲酰基类化合物 的重要途径 ${ }^{[83-85]}$. 2019 年, Jang 等 ${ }^{[86]}$ 报道了苄胺类化合 物或含活性亚甲基类化合物为底物, 以氧气为氧化剂, $1,3,4,6,7,8$-六氢- $2 H$-嘧啶并 $[1,2-a]$ 嘧啶为碱, 合成一系 列苯甲酰胺类化合物或酮的方法，收率达 $89 \%$ ，反应不 需要过渡金属的参与, 该反应提供了一种有效的将活泼 亚甲基直接氧化成羰基的方法(Eq. 48).

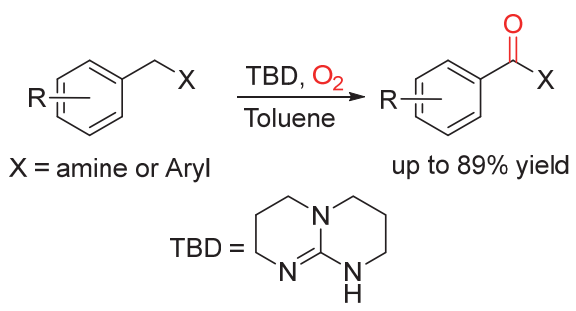

在该反应中, 首先氧气将活泼亚甲基氧化为过氧化 物, 然后在有机碱 TBD 的作用下脱去一分子水得芳甲 酰胺类化合物(Scheme 23).<smiles>[X]C(=O)[Al]C(O)[18O]C([Y])OO</smiles>

图式 23 通过亚甲基氧化合成芳甲酰基化合物可能的反应机 理

Scheme 23 Possible reaction mechanism for synthesis of aroyl compounds by methylene oxidation

2020 年, 吴安心课题组 ${ }^{[87]}$ 报道了以芳基乙酮类化 合物为芳甲酰基羰基源，与苯胺类化合物在二甲基亚砜 溶液中一锅法通过 $\mathrm{C}-\mathrm{C}$ 断裂、环合、 $\mathrm{C}-\mathrm{H}$ 活化等步 骤合成芳甲酰基取代的苯并嘧啶酮类化合物, 收率为 $50 \% \sim 60 \%$ (Eq. 49).

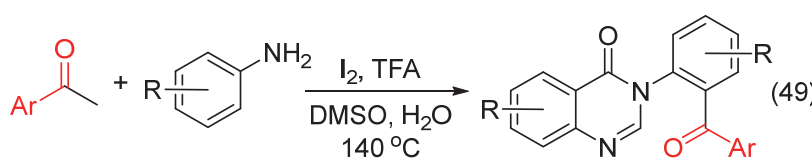

\section{4 总结与展望}

综上所述，以过渡金属催化的偶联反应和以自由基 机理的芳甲酰基化反应受到了极大的关注. 然而, 这些 反应目前尚处在基础研究阶段，实现工业领域的大规模 生产面临着巨大挑战. 光催化反应具有安全、无毒、易 操作等特点, 符合绿色化学的发展理念. 近年来, 光催 化单电子转移诱导自由基串联反应的快速发展极大地 促进了传统的由过渡金属催化向光催化的芳甲酰基化 反应的发展进程，不断地拓展了芳甲酰基化反应的应用 领域，同时也是科研工作者不断前进和探索的方向. 为 此，本文希望通过对芳酮类化合物的合成机理的详细探 讨和分类，为其合成新方法的开发提供思路和工业化生 产提供理论指导.

\section{References}

[1] Zhu, X.-L.; Tian, X.-Q.; Xu, H.-H.; Wang, H.-M.; Chen, Q.-H.; Zeng, X.-H. Bioorg. Med. Chem. Lett. 2020, 30, 127554.

[2] Duan, J. X.; Cai, X.; Meng, F.; Lan, L.; Hart, C.; Matteucci, M. J. Med. Chem. 2007, 50, 1001.

[3] Mai, A.; Massa, S.; Ragno, R.; Cerbara, I.; Jesacher, F.; Loidl, P.; Brosch, G. J. Med. Chem. 2003, 46, 512.

[4] Han, Y.; Tian, Y.; Wang, R.; Fu, S.; Jiang, J.; Dong, J.; Qin, M.; Hou, Y.; Zhao, Y. Bioorg. Chem. 2020, 104, 104197.

[5] Turan-Zitouni, G.; Yurttaş, L.; Kaplancıkl1, Z. A.; Can, Ö. D.; Demir Özkay, Ü. Med. Chem. Res. 2015, 24, 2406.

[6] Patch, R. J.; Brandt, B. M.; Asgari, D.; Baindur, N.; Chadha, N. K.; Georgiadis, T.; Cheung, W. S.; Petrounia, I. P.; Donatelli, R. R.; Chaikin, M. A.; Player, M. R. Bioorg. Med. Chem. Lett. 2007, 17, 6070.

[7] Wang, L.; Guo, D.-G.; Wang, Y.-Y.; Zheng, C.-Z. RSC Adv. 2014, 4, 58895 .

[8] Rane, R. A.; Telvekar, V. N. Bioorg. Med. Chem. Lett. 2010, 20 5681.

[9] Çınarlı, M.; Yüksektepe Ataol, Ç.; Çınarlı, E.; İdil, Ö. J. Mol. Struct. 2020, 1213, 128152.

[10] Rodríguez, N.; Goossen, L. J. Chem. Soc. Rev. 2011, 40, 5030.

[11] Bode, K.-D.; Dieterich, D.; Eistert, B.; Gipp, R.; Henecka, H.; Herlinger, H.; Jira, R.; Kramer, D.; Kabbe, H.-J.; Lüttringhaus, A.; Regitz, M.; Schellhammer, C.-W.; Söll, H.; Stetter, H.; Wilms, H.; Wingler, F. Methoden der Organischen Chemie (Houben-Weyl) Thieme, Stuttgart, 1973, p. 268.

[12] Zhao, W.; Liu, W. Chin. J. Org. Chem. 2015, 35, 55 (in Chinese). (赵蔚, 刘伟, 有机化学, 2015, 35, 55.)

[13] Molle, G.; Bauer, P. J. Am. Chem. Soc. 1982, 104, 3481

[14] Bosque, I.; Chinchilla, R.; Gonzalez-Gomez, J. C.; Guijarro, D.; Alonso, F. Org. Chem. Front. $2020,7,1717$.

[15] Brennführer, A.; Neumann, H.; Beller, M. Angew. Chem., Int. Ed. 2009, $48,4114$.

[16] Swain, C. G. J. Am. Chem. Soc. 1947, 69, 2306.

[17] Arthuis, M.; Pontikis, R.; Florent, J.-C. Org. Lett. 2009, 11, 4608.

[18] Zhao, M.-N.; Ran, L.; Chen, M.; Ren, Z.-H.; Wang, Y.-Y.; Guan, Z.-H. ACS Catal. 2015, 5, 1210.

[19] Tjutrins, J.; Arndtsen, B. A. J. Am. Chem. Soc. 2015, 137, 12050.

[20] Lian, Z.; Friis, S. D.; Skrydstrup, T. Chem. Commun. 2015, 51, 1870.

[21] Garrison Kinney, R.; Tjutrins, J.; Torres, G. M.; Liu, N. J.; Kulkarni, O.; Arndtsen, B. A. Nat. Chem. 2018, 10, 193.

[22] Levesque, T. M.; Kinney, R. G.; Arndtsen, B. A. Chem. Sci. 2020, 11,3104 .

[23] Quesnel, J. S.; Fabrikant, A.; Arndtsen, B. A. Chem. Sci. 2016, 7, 
295.

[24] Lagueux-Tremblay, P.-L.; Fabrikant, A.; Arndtsen, B. A. ACS Catal. 2018, 8,5350

[25] Odell, L. R.; Russo, F.; Larhed, M. Synlett 2012, 23, 685.

[26] Ningegowda, R.; Bhaskaran, S.; Sajith, A. M.; Aswathanarayanappa, C.; Padusha, M. S. A.; Shivananju, N. S.; Priya, B. S. Aust. J. Chem. 2017, 70, 44.

[27] Darbem, M. P.; Kanno, K. S.; de Oliveira, I. M.; Esteves, C. H. A.; Pimenta, D. C.; Stefani, H. A. New. J. Chem. 2019, 43, 696.

[28] Dong, Y.; Sun, S.; Yang, F.; Zhu, Y.; Zhu, W.; Qiao, H.; Wu, Y.; Wu, Y. Org. Chem. Front. 2016, 3, 720 .

[29] Jafarpour, F.; Rashidi-Ranjbar, P.; Kashani, A. O. Eur. J. Org. Chem. 2011, 2011, 2128.

[30] Sun, N.; Sun, Q.; Zhao, W.; Jin, L.; Hu, B.; Shen, Z.; Hu, X. Adv. Synth. Catal. 2019, 361, 2117.

[31] Ismael, A.; Gevorgyan, A.; Skrydstrup, T.; Bayer, A. Org. Process Res. Dev. 2020, 24, 2665.

[32] Ryotaro, N.; Hideki, Y.; Koichiro, O. Chem. Lett. 2011, 40, 904.

[33] Roy, T.; Rydfjord, J.; Sävmarker, J.; Nordeman, P. Tetrahedron Lett. 2018, 59,1230

[34] Wang, Z.; Yin, Z.; Wu, X.-F. Chem.-Eur. J. 2017, 23, 15026.

[35] Peng, J.-B.; Geng, H.-Q.; Li, D.; Qi, X.; Ying, J.; Wu, X.-F. Org. Lett. 2018, 20, 4988 .

[36] Ying, J.; Le, Z.; Wu, X.-F. Org. Chem. Front. 2020, 7, 2757.

[37] Ying, J.; Le, Z.; Bao, Z.-P.; Wu, X.-F. Org. Chem. Front. 2020, 7, 1006.

[38] Scheffold, R.; Orlinski, R. J. Am. Chem. Soc. 1983, 105, 7200.

[39] Arisawa, M.; Tanii, S.; Yamaguchi, M. Chem. Commun. 2014, 50, 15267.

[40] Zhang, Y.; Chen, J. L.; Chen, Z. B.; Zhu, Y. M.; Ji, S. J. J. Org. Chem. 2015, 80, 10643.

[41] Ying, J.; Fu, L.-Y.; Zhou, C.; Qi, X.; Peng, J.-B.; Wu, X.-F. Eur. J. Org. Chem. 2018, 2018, 2780.

[42] Wang, Y.; Zhou, Y.; Lei, M.; Hou, J.; Jin, Q.; Guo, D.; Wu, W. Tetrahedron 2019, 75, 1180.

[43] Geng, H.-Q.; Wang, L.-C.; Hou, C.-Y.; Wu, X.-F. Org. Lett. 2020, 22,1160 .

[44] Higashi, S.; Uno, S.; Ohsuga, Y.; Noumi, M.; Saito, R. Tetrahedron Lett. 2020, 61, 152466.

[45] Li, Y.; Xiong, W.; Zhang, Z.; Xu, T. J. Org. Chem. 2020, 85, 6392.

[46] Weng, Y.; Yang, T.; Chen, H.; Chen, Z.; Zhu, M.; Zhan, X. ChemistrySelect 2019, 4, 14233.

[47] Gong, J.; Hu, K.; Shao, Y.; Li, R.; Zhang, Y.; Hu, M.; Chen, J. Org. Biomol. Chem. 2020, 18, 488.

[48] Tlili, A.; Schranck, J.; Pospech, J.; Neumann, H.; Beller, M. Angew. Chem., Int. Ed. 2013, 52, 6293.

[49] Li, W.; Zhang, S.; Feng, X.; Yu, X.; Yamamoto, Y.; Bao, M. Org. Lett. 2021, 23, 2521.

[50] Luo, L.; Zhou, Z.; Zhu, J.; Lu, X.; Wang, H. Tetrahedron Lett. 2016, 57,4987 .

[51] Chatupheeraphat, A.; Liao, H.-H.; Srimontree, W.; Guo, L.; Minenkov, Y.; Poater, A.; Cavallo, L.; Rueping, M. J. Am. Chem. Soc. 2018, 140, 3724.

[52] Liu, Z.; Wang, P.; Yan, Z.; Chen, S.; Mu, T. Beilstein J. Org. Chem. 2020, 16,645

[53] Zhang, Q.; Li, J.; Li, J.; Yuan, S.; Li, D. Tetrahedron Lett. 2020, 61, 152399

[54] Monir, K.; Kumarbagdi, A.; Mishra, S.; Majee, A.; Hajra, A. $A d v$. Synth. Catal. 2014, 356, 1105

[55] Kaswan, P.; Pericherla, K.; Saini, H. K.; Kumar, A. RSC Adv. 2015,
5,3670 .

[56] Li, J. J.; Song, C.; Cui, D.-M.; Zhang, C. Org. Biomol. Chem. 2017, $15,5564$.

[57] Behera, A.; Ali, W.; Guin, S.; Khatun, N.; Mohanta, P. R.; Patel, B. K. RSC Adv. 2015, 5, 33334

[58] Pipaliya, B. V.; Chakraborti, A. K. J. Org. Chem. 2017, 82, 3767.

[59] Zhao, B.; Shang, R.; Cheng, W.-M.; Fu, Y. Org. Chem. Front. 2018, 5,1782 .

[60] Cao, H.; Pu, W.; Zhang, J.; Yan, P.; Zhang, J.; Xu, S. Synlett 2020, $31,1287$.

[61] Khatun, N.; Banerjee, A.; Santra, S. K.; Behera, A.; Patel, B. K. RSC Adv. 2014, 4, 54532.

[62] Joe, C. L.; Doyle, A. G. Angew. Chem., Int. Ed. 2016, 55, 4040.

[63] Wang, H.; Zhou, S.-L.; Guo, L.-N.; Duan, X.-H. Tetrahedron 2015 71,630 .

[64] Yuan, J.-W.; Yin, Q.-Y.; Yang, L.-R.; Mai, W.-P.; Mao, P.; Xiao, Y.-M.; Qu, L.-B. RSC Adv. 2015, 5, 88258.

[65] Pimpasri, C.; Sumunnee, L.; Yotphan, S. Org. Biomol. Chem. 2017, $15,4320$.

[66] Wang, G.-Z.; Shang, R.; Cheng, W.-M.; Fu, Y. Org. Lett. 2015, 17, 4830.

[67] Wang, C.-M.; Song, D.; Xia, P.-J.; Wang, J.; Xiang, H.-Y.; Yang, H. Chem.-Asian J. 2018, 13, 271.

[68] Lei, Z.; Banerjee, A.; Kusevska, E.; Rizzo, E.; Liu, P.; Ngai, M. Y. Angew. Chem., Int. Ed. 2019, 58, 7318.

[69] Meng, Q. Y.; Döben, N.; Studer, A. Angew. Chem., Int. Ed. 2020, $59,19956$.

[70] Bergonzini, G.; Cassani, C.; Wallentin, C.-J. Angew. Chem., Int. Ed. 2015, 54, 14066

[71] Dong, S.; Wu, G.; Yuan, X.; Zou, C.; Ye, J. Org. Chem. Front. 2017, $4,2230$.

[72] Xu, S.-M.; Chen, J.-Q.; Liu, D.; Bao, Y.; Liang, Y.-M.; Xu, P.-F. Org. Chem. Front. 2017, 4, 1331.

[73] Guo, W.; Lu, L.-Q.; Wang, Y.; Wang, Y.-N.; Chen, J.-R.; Xiao, W.-J. Angew. Chem., Int. Ed. 2015, 54, 2265.

[74] Majek, M.; Jacobi von Wangelin, A. Angew. Chem., Int. Ed. 2015, $54,2270$.

[75] Koziakov, D.; Jacobi von Wangelin, A. Org. Biomol. Chem. 2017, $15,6715$.

[76] Xu, G.-Q.; Xiao, T.-F.; Feng, G.-X.; Liu, C.; Zhang, B.; Xu, P.-F. Org. Lett. 2021. 23, 2846.

[77] Zhu, H.-L.; Zeng, F.-L.; Chen, X.-L.; Sun, K.; Li, H.-C.; Yuan, X.-Y.; Qu, L.-B.; Yu, B. Org. Lett. 2021, 23, 2976.

[78] Zhang, H.; Shi, R.; Ding, A.; Lu, L.; Chen, B.; Lei, A. Angew. Chem., Int. Ed. 2012, 51, 12542.

[79] Jafarpour, F.; Abbasnia, M. J. Org. Chem. 2016, 81, 11982.

[80] Gouthami, P.; Chavan, L. N.; Chegondi, R.; Chandrasekhar, S. $J$. Org. Chem. 2018, 83, 3325.

[81] Pan, Z.; Song, C.; Zhou, W.; Cui, D.-M.; Zhang, C. New. J. Chem 2020, 44, 6182.

[82] Chauhan, J.; Luthra, T.; Sen, S. Eur. J. Org. Chem. 2018, 2018 , 4776.

[83] Yamada, Y. M. A.; Arakawa, T.; Hocke, H.; Uozumi, Y. Angew. Chem., Int. Ed. 2007, 46, 704.

[84] Han, L.; Xing, P.; Jiang, B. Org. Lett. 2014, 16, 3428.

[85] Caron, S.; Dugger, R. W.; Ruggeri, S. G.; Ragan, J. A.; Ripin, D. H. B. Chem. Rev. 2006, 106, 2943

[86] Lee, S.; Kim, S. A.; Jang, H.-Y. ACS Omega 2019, 4, 17934.

[87] Zhao, P.; Yu, X.-X.; Zhou, Y.; Geng, X.; Wang, C.; Huang, C.; Wu, Y.-D.; Zhu, Y.-P.; Wu, A.-X. Org. Lett. 2020, 22, 7103. 